University of Rhode Island

DigitalCommons@URI

Open Access Dissertations

1994

\title{
Individual Versus Multidisciplinary Team Decision Making
}

Andrew D. Aspel

University of Rhode Island

Follow this and additional works at: https://digitalcommons.uri.edu/oa_diss

\section{Recommended Citation}

Aspel, Andrew D., "Individual Versus Multidisciplinary Team Decision Making" (1994). Open Access

Dissertations. Paper 967.

https://digitalcommons.uri.edu/oa_diss/967

This Dissertation is brought to you for free and open access by DigitalCommons@URI. It has been accepted for inclusion in Open Access Dissertations by an authorized administrator of DigitalCommons@URI. For more information, please contact digitalcommons-group@uri.edu. 


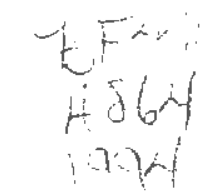

INDIVIDUAL VERSUS MULTIDISCIPLINARY TEAM DECISION MAKING BY ANDREW D. ASPEL

A DISSERTATION SUBMITTED IN PARTIAL FULFILLMENT OF THE REQUIREMENTS FOR THE DEGREE OF DOCTOR OF PHILOSOPHY

IN PSYCHOLOGY

UNIVERSITY OF RHODE ISLAND

$$
2,947992
$$




\begin{abstract}
The present study compared individual against multidisciplinary team diagnostic and placement decisions. Specifically, this study examined if teams were more likely than individuals to incorporate relevant base-rate information into their decisions and to ignore irrelevant, or illusory, information (degree of intersubtest scatter). Members of 20 teams were asked to evaluate four case scenarios. Each team consisted of a school psychologist, an administrator, and an educational diagnostician. For two of the cases, base-rate information was manipulated; on the other two cases, intersubtest scatter on the WISC-III was manipulated. Participants evaluated one set of cases as a team, and the other set of cases individually. Individual responses were pooled and compared to team responses. Results indicated that teams were not any more likely than individuals to incorporate relevant information into their diagnostic and placement decisions. Teams were just as likely as individuals, however, to incorporate irrelevant information into their decisions. Clinical and research implications of the results are discussed.
\end{abstract}




\section{Acknowledgments}

I would like to thank Dr. W. Grant Willis and Dr. David Faust for their guidance, patience and support throughout this project. I would also like to thank the other members of my committee Dr. Susan Brady and Dr. Susie Kim. Their expertise was extremely helpful. I would also like to thank the members of the 20 multidisciplinary teams who took time from their demanding schedules and participated in this study. 
page

Purpose and Justification 1

Individual versus Team Decision making 1

Steiners Model 2

$\begin{array}{ll}\text { Brainstorming } & 4\end{array}$

Complex Problems

Conclusions

Criticisms of the Research $\quad 6$

$\begin{array}{ll}\text { Multidisciplinary Team Research } & 7\end{array}$

Observational and Survey Research $\quad 8$

$\begin{array}{ll}\text { Experimental Research } & 10\end{array}$

$\begin{array}{ll}\text { Summary } & 11\end{array}$

$\begin{array}{lr}\text { Errors in Clinical Judgment } & 12\end{array}$

Illusory Correlation $\quad 12$

Base-rate Fallacy $\quad 12$

$\begin{array}{ll}\text { Clinical Judgment and School Psychology } & 13\end{array}$

$\begin{array}{ll}\text { Hypotheses } & 14\end{array}$

$\begin{array}{ll}\text { Method } & 15\end{array}$

$\begin{array}{ll}\text { Subjects } & 15\end{array}$

$\begin{array}{ll}\text { Case Materials } & 16\end{array}$

$\begin{array}{ll}\text { Procedure } & 17\end{array}$

$\begin{array}{ll}\text { Design } & 18\end{array}$

$\begin{array}{ll}\text { Results } & 21\end{array}$

$\begin{array}{ll}\text { Perceived Validity of the Case Scenarios } & 21\end{array}$

Dealing with Unequal Variances $\quad 22$

Placement Scale Analyses $\quad 22$

Base-Rate Conditions $\quad 22$

$\begin{array}{ll}\text { Mixed groups } & 23\end{array}$

Intact groups $\quad 23$

$\begin{array}{ll}\text { Scatter Conditions } & 24\end{array}$

$\begin{array}{ll}\text { Mixed groups } & 24\end{array}$

$\begin{array}{ll}\text { intact groups } & 24\end{array}$

Probability and Confidence Analyses $\quad 25$ 
$\begin{array}{ll}\text { Base-Rate Conditions } & 25 \\ \text { Mixed groups } & 25 \\ \text { Intact groups } & 27 \\ \text { Scatter Conditions } & 28 \\ \text { Mixed groups } & 28 \\ \text { Intact groups } & 31\end{array}$

Discussion 34

Validity of the Case Scenarios $\quad 34$

Dealing with Unequal Variances $\quad 35$

Placement Scale $\quad 35$

Base-Rate Conditions $\quad 35$

Scatter Conditions $\quad 35$

Probability and Confidence Ratings $\quad 36$

Base-Rate Conditions $\quad 36$

$\begin{array}{ll}\text { Scatter Conditions } & 37\end{array}$

Interpretation of the Results 38

Limitations 41

Conclusions and Implications $\quad 42$

Appendix A 46

Appendix B 56

Tables $\quad 57$

$\begin{array}{ll}\text { Bibliography } & 79\end{array}$ 
Table

1 ANOVA Table for Placement Scale: Base-Rate Conditions, Mixed Groups

2 ANOVA Table for Placement Scale: Base-Rate Conditions, Intact Groups

3 ANOVA Table for Placement Scale: Scatter Conditions, Mixed Groups

4 ANOVA Table for Placement Scale: Scatter Conditions, Intact Groups

5 ANOVA Table for Probability: Base-Rate Conditions, Mixed Groups

6 ANOVA Table for Confidence: Base-Rate Conditions, Mixed Groups

7 Mean Differences in Probability among Diagnoses: Base-rate Conditions, Mixed Groups

8 Mean Differences in Confidence among Diagnoses: Base-rate Conditions, Mixed Groups

9 ANOVA Table for Probability: Base-Rate Conditions, Intact Groups 65

10 ANOVA Table for Confidence: Base-Rate Conditions, Intact Groups

11 Mean Differences in Probability among Diagnoses: Base-rate Conditions, Intact Groups

12 Mean Differences in Confidence among Diagnoses: Base-rate Conditions, Intact Groups

13 ANOVA Table for Probability: Scatter Conditions, Mixed Groups

14 Simple Effects for Diagnosis X Decision Interaction: Scatter Conditions, Mixed Groups

15 Simple Effects for Scatter X Diagnosis Interaction: Scatter Conditions, Mixed Groups

16 ANOVA Table for Confidence: Scatter Conditions, Mixed Groups

17 Mean Differences in Confidence among Diagnoses: Scatter Conditions, Mixed Groups

18 ANOVA Table for Probability: Scatter Conditions, Intact Groups

19 Simple Effects for Decision X Diagnosis Interaction: Scatter Conditions, Intact Groups

20 Simple Effects for Scatter X Diagnosis Interaction: Scatter Conditions, Intact Groups

21 ANOVA Table for Confidence: Scatter Conditions, Intact Groups

22 Mean Differences in Confidence among Diagnoses: Scatter Conditions, Intact Groups 


\section{INDIVIDUAL VERSUS MULTIDISCIPLINARY TEAM DECISION MAKING}

\section{Purpose and Justification}

The primary purpose of the present study was to compare individual against multidisciplinary team decisions for classifiying and providing of special-educational services to children and youth with disabilities. The rules and regulations for implementing the Education for All Handicapped Children Act of 1973 (Public Law 94142) specify that eligibility for special-education services must be determined through a multidisciplinary team format. Pfeiffer (1980) argued that the intention behind this mandate was that group decisions safeguard against individual errors in judgment and therefore are more likely to yield accurate evaluation, classification, and placement decisions. The rationale for team decision making largely is based on the premise that individual experience and knowledge can be pooled effectively during the decisionmaking process, thereby improving decision-making accuracy. Although this assumption is sensible at an intuitive level, there is little empirical evidence to support it (Yoshida, 1983).

This section begins by reviewing research comparing team and individual performance conducted in the areas of social and organizational psychology. Next, criticisms of this research and improvement attempts are reported. This is followed by a description of research investigating multidisciplinary teams, including survey, observational, and experimental investigations. The section concludes with a description of the research questions that were investigated in this study.

Individual versus Team Decision Making

There currently is a dearth of research about individual versus team decision making focusing on special-education placement (Pfeiffer \& Naglieri, 1983; Vantour, 
1976). Social and organizational psychologists, however, have shown interest in the differences between individual versus team processing, especially for solving problems in business and military settings. For example, Hill (1982) reviewed a number of studies examining individual versus team processing, focusing on research where individuals working separately were contrasted with groups working collaboratively on products. Areas of investigation have included (a) learning and concept attainment, (b) concept mastery, (c) creativity, and (d) problem solving.

\section{Steiner's Model}

Hill (1982) reported that much of this research is based on Steiner's (1966) model of group decision-making. This model, known as the complementary task model, suggests that each group member has unique abilities and when these abilities are pooled, groups outperform individuals. Laughlin, Branch, and Johnson (1969) investigated Steiner's model using a concept-mastery test. They found that the accuracy of this model increased with the ability level of the group. For example, an individual working with a partner of greater ability seemed to outperform an individual working alone or with a partner of lesser ability. When homogeneous groups were used, Steiner's model was supported only for groups of high-ability individuals. Here, teams composed of high-ability members outperformed high-ability individuals, but medium and low-ability groups did not differ from medium and low-ability individuals. Results also suggested that in larger heterogeneous groups, the performance of a high-ability group member could be adversely affected by members with lower ability.

Additional studies have used tasks with readily recognizable solutions (Laughlin \& Blitz, 1975). With these kinds of tasks, lower-ability and medium-ability group members seemed to learn from each other and thereby increased their performance. Group members, however, did not always share resources and, therefore, group performance did not equal the performance of the group's best member. 
These studies have provided only limited support for Steiner's (1966) model. Essentially, sharing resources seems to occur more frequently in groups where the level of ability among members is mixed. When resources are not shared among the group members, however, the level of group performance is unlikely to equal the performance of the best member.

Other studies of group problem solving have expanded on Steiner's (1966) model and have suggested a system of checks and balances that may accompany a general pooling of information (Hill, 1982). This system may provide the group with a way to correct individual errors. Here, previous research has indicated that although groups generally took longer than individuals to solve problems, groups had more correct solutions than individuals. Incorrect suggestions usually were rejected by another member of the group providing a system of checks. The quality of the group performance, however, largely was influenced by the presence of a competent member. Groups produced more solutions than individuals, but groups did not generate more solutions than the best member or statistical aggregates of individuals (Faust, 1959).

In contrast, when problems are complex or difficult, groups may perform better than their best member. Here, the most competent member may need to draw on the resources of other group members to complete the task. Shaw and Ashton (1976) found that easy puzzles were completed quickly by a competent group member; other members seemed to accept the solution. That is, for an easy task, the number of successful groups was proportional to the number of individuals who could solve the problem. When the puzzle task was more difficult, the proportion of successful groups was greater than the proportion of successful individuals. Shaw and Ashton suggested that these results indicated that groups pooled their resources when no one individual could solve the problem.

Hill (1982) suggested that for more abstract tasks, group superiority over individuals could best be explained as an aggregation of resources. This was similar to 
the complementary model proposed by Steiner (1966). This pooling of resources was more likely to take place when the task was difficult and no one individual could solve the problem. For easier tasks, group performance was most likely dictated by one competent member. Hill warned that high-ability members would be uncommon if the distribution of abilities followed a normal curve. As a result, most large groups would be composed of a large number of medium-ability members. Previously mentioned research involving creativity and concept-mastery tasks indicated that a large number of low- and medium-ability members actually may hinder performance.

\section{Brainstorming}

Brainstorming tasks also have been used to investigate the differences between individual and group processing. Brainstorming tasks are somewhat different in that the object is to generate many possible solutions (i.e., divergent production) instead of only one correct answer (i.e., convergent production). Osborn (1966) believed that groups could stimulate the production of ideas beyond the number that could be produced by an individual. His hypothesis was supported in a study investigating divergent production of fourth-grade students acting individually and in groups (Buchanan \& Lindgreen, 1973).

A number of different kinds of problems have been used to compare group and individual brainstorming. One kind is based more on fantasy. One example is asking what would happen if, after this year, everyone was born with an extra thumb. Another has more social relevance. Here, an example is asking what steps should be taken with increased enrollment in schools to ensure that instruction remains effective, that is, children receive the attention they need to learn. Despite the kind of problem used, scores from statistical pooling were equal to or greater than those of groups (Harari \& Graham, 1975). In this case, statistical pooling is a process where individual solutions are combined into a set of responses; redundant responses are then discarded. In some instances, statistical pooling also was found to produce a higher number of unique ideas 
than groups. There also was some evidence that the group interaction may sometimes hinder the number of responses produced. Studies have found that idea production increased when ideas were pooled in writing but decreased when information was pooled through discussion (Taylor, Berry, \& Block, 1958). The group interaction seemed to inhibit some responses, and more responses were produced when group members wrote solutions individually and then discussed their solutions collectively.

\section{Complex Problems}

Complex problems also have been used to assess the differences between individual and group processing. Complex problems are similar to brainstorming tasks in that there can be more than one correct solution. For example, Tuckman and Lorge (1962) asked airforce officers to formulate a plan for getting troops across a road containing mines that could not be neutralized or removed. The results of this study indicated that group solutions were always superior to individual solutions. Tuckman and Lorge had officers practice the problems as individuals and then either solve the problems as individuals or in groups. They found that group performance was superior to individuals but that groups sometimes did not use some of the best ideas previously produced by their members. Of the groups, $79 \%$ were as good or better than their best member's score, whereas $11 \%$ did not perform as well as their best member. This study suggested that complex problems often are solved better as groups than as individuals but the group format may sometimes hinder the performance of the group's best member.

\section{Conclusions}

Hill (1982) concluded that the majority of this research has shown that group performance is superior to the performance of the average individual. Group performance, however, often was not as good as a group's most competent member. This was somewhat dependent on the kind of tasks that was used, level of difficulty, as well composition of the group. There were instances where an exceptional individual 
outperformed a team. In comparisons between groups and a statistical pooling of group resources, the statistical pooling was usually superior.

\section{Criticisms of the Research}

Michaelson, Watson, and Black (1989) suggested that the lack of unequivocal support for the superiority of group decisions over the group's best member may be due to the artificial nature of the tasks, groups, or settings in which the research was conducted. For example, much of the research that has been conducted studied groups that were assembled solely for the purpose of the investigations. In many cases the groups were assembled for less than an hour. Participants usually also were required to work on a task that was both unfamiliar to them and was not consistent with the setting in which they were examined. In order to address these issues, Michaelson et al. conducted a study using groups that had experience working together, and the task was both familiar and appropriate to the setting.

Participants in their study were undergraduate students enrolled in organizational-behavioral courses. A majority of the class time was spent working on group problem-solving tasks and students were assigned to a group for the duration of the class. The data for this study were from individual and group tests that were a normal part of the course instruction. In the actual testing process, individuals completed their test first and then, when other group members completed the exam, they took the exam again as a group. The group's cumulative scores over six exams then were compared with scores of their average and most knowledgeable members. All of the groups outperformed their average member and $97 \%$ of the groups outperformed their best member. Michaelson et al. (1989) concluded that when a realistic task is used, and the groups have experience working together, groups may outperform their best member.

In a follow-up study using a similar design, Watson, Michaelson, and Sharp (1991) compared group and best-member performance over an extended period of time. 
The percentage by which the group outperformed the group's best member was calculated, as well as a ratio in which the denominator was the maximum score possible minus the best member's score, and in which the numerator was the group score minus the best member's score. This ratio was developed as an attempt to measure how much a group added over its best member's score. The ratio scores supported their hypothesis and indicated that group-decision-making effectiveness improved with increased experience, because ratios increased over time. Watson et al. concluded that given a realistic task, with groups who have worked together previously, groups not only outperform the best member, but the proportion by which they outperform the best member increases over time.

Unfortunately, however, the methodology used does not rule out the possibility of practice effects. Each team was given the same task that they previously had completed as individuals. The group performance may have improved simply due to repeated exposure to the same task. Despite this flaw, the criticisms of the previous research remain valid. Studies attempting to investigate differences between individuals and groups should use tasks that are appropriate to the setting and that are realistic. Groups that are investigated should consist of members who have had some previous experience working together. These criteria were not present in the majority of the research.

\section{Multidisciplinary Team Research}

Although there is extensive research comparing team and individual performance in social and organizational psychology, little research exists investigating the multidisciplinary team (MDT) process in educational settings. This is an important area for research because MDTs are required for the determination of eligibility and placement for special-educational services. MDTs originally were established as an attempt to reduce the misclassification of students in special-education decisions. PL 
94-142 required that decisions regarding whether or not a student qualified for special education services be made by a MDT. The team was supposed to use specific criteria and different sources of information in its decision (Yoshida, 1983). The reason given for the selection of the MDT model was that groups offer different perspectives of children and could be used to prevent biased decisions made by an individual decision maker (Yoshida, 1983). This reasoning was similar to Steiner's complementary model of group processing. Both suggested a sharing of member resources in order to improve decision making. In the early 1980s, however, the usefulness of the MDT model started to be questioned. Recent reviews of the research on MDTs suggested that there was insufficient evidence to show that MDTs make better decisions than individuals, and that the MDT decision making process may be flawed (Yoshida, 1983).

Research investigating the practice of MDTs in schools began relatively recently. Unlike the research in group decision making in the areas of social and organizational psychology, relatively little team research in school psychology has been conducted through experimentation. The majority of the research on MDTs has been either observational or conducted through surveys. This research suggests that MDTs may not be functioning the way that they were intended.

\section{Observational and Survey Research}

Ysseldyke, Algozzine, and Mitchell (1982) developed an observational method for collecting data on the characteristics of effective team meetings. This study showed some favorable and unfavorable results. An unfavorable finding was that the purpose of the meeting was only stated in $35 \%$ of the meetings. Instead of having a formal purpose statement, $84 \%$ of the meetings began with a referral statement. A more favorable finding was that in most of the team meetings there was some attempt to relate the data to the actual nature of the problem $(81 \%)$. Other findings were that behavioral data were rarely considered, and in $88 \%$ of the teams the only data mentioned came from normreferenced tests. 
Other observational research indicated that although there tended to be a high degree of congruence between the category for which a student was referred and the category for which a student was placed, especially if the teacher referred the student (Foster, Ysseldyke, Casey, \& Thurlow, 1984), teachers did not participate much in the meetings, or they participated in a superficial manner (Ysseldyke, Algozzine, \& Allen, 1981). This was an alarming finding considering it is teachers who implement decisions made by teams.

Surveys of MDT participants generally have been aimed at determining participant satisfaction with the team process and identifying potential problems. A survey of MDT members in the Connecticut area (Yoshida, Fenton, Maxwell, \& Kaufman, 1978) revealed that members of different professions differed in their self perceptions of their participation during meetings. School psychologists, social workers, counselors, and administrators viewed themselves as participating more than specialor regular-education teachers. Members who participated more also reported more satisfaction with the team process. This survey finding corresponded to observational studies of teams showing little participation by teachers in the meetings.

Teachers were not the only professionals who wanted to be more involved in the team process. Kabler and Carton (1981) asked team members to compare what was actually happening on their teams to what they would like to happen. All members of the MDT reported that their actual level of participation was below their desired level of participation. School psychologists and administrators rated their participation significantly higher than teachers and parents.

Pffeifer (1981) also conducted a survey of MDT members. This survey asked participants to identify problems that they felt pertained to their team. One of the most frequently noted problems was a lack of programs from which to select. This issue was one of primary concern to all team members. Moderate problem areas included: (a) fiscal restraints, (b) lack of opportunity for follow up, (c) lack of time to discuss 
individual cases, and (d) cases that were difficult to define. Unlike the survey previously discussed, these concerns had little to do with the actual decision-making process. The majority of these concerns were related to finances and time. The participants of this survey seemed to feel that teams were not being granted the resources required for optimal functioning.

These observational and survey studies of MDTs suggest that they may not be functioning in the way that was intended in PL 94-142. Decisions were supposed to result from input from different sources, and by having more people make the decisions, biased and inaccurate decisions were hoped to be avoided. Instead, research indicates that many professionals on the teams do not have much input into the decisions. This suggests that the actual aggregation of resources on a team may be more limited than was intended when the MDT structure was mandated. If this is true, then the decisions made by the team may not differ from the most dominant team members. The team decisions may not be any better or different from the decision of the most dominant individual.

\section{Experimental Research}

In an early study, Vantour (1976) found that special-educational placement decisions made by groups were more accurate than placement decisions made by the same individuals acting alone. In this study, accuracy was assessed based on a comparision with expert ratings. Pffeifer and Naglieri (1983) subsequently conducted a similar investigation of individual versus MDT decisions. Members of MDTs were given two cases and asked to make placement decisions for the two cases. The placement decisions were indicated on a scale that comprised seven educational placements, ranging on a continuum from least-restrictive to most-restrictive environment. The team members first made placement decisions as individuals and then discussed placements as a team a week later. Experts also were asked to rate the cases. The team, individual, and expert decisions were compared. 
Results of this study indicated that there was less variability in the MDT than individual decisions and that the MDT decisions more closely matched the expert decisions. Pffeifer and Naglieri concluded that this study provided support for the superiority of MDT over individual decisions. There were, however, some methodological flaws in this study. For example, variability was compared from two samples of unequal numbers. There were 22 team responses that were compared to 86 individual responses. One would expect there to be differences in variability simply due to the differences in the number of responses. Therefore, this study failed to present clear evidence that MDTs made more accurate decisions than individuals.

\section{Summary}

The current research does not provide convincing evidence that multidisciplinary teams make better decisions than individuals. Research in social and organizational psychology comparing group and individual processing indicates that groups generally outperform the average member of a team but only outperform the team's best member when that member cannot attain a solution alone. The research in this area, however, has been criticized for the tasks used as well as for the fact that the majority of the teams studied had little experience working together.

Although research in school psychology investigating MDTs has used existing teams, the majority of this research has been conducted by observational or survey methods, and therefore has provided limited information. The results of these investigations suggest that the team process may not be functioning in the manner intended. The superiority of MDT decisions over individual decisions, therefore, is questionable.

The present study compared MDT against individual decision making. Specifically, this dissertation addressed whether or not there were any differences between team and pooled individual decisions, and the extent to which these differences favored a team decision-making approach. Two approaches were used to investigate this 
issue. The first approach involved an investigation of placement decisions. Do team special-education placement decisions differ from individual special-education placement decisions? The second approach involved a comparison of the accuracy of team and individual decision-making through an investigation of susceptibility to errors in clinical judgment. In order to examine potential differences in the accuracy of the decision-making processes between groups and individuals, susceptibility to two clinical-judgment errors were examined.

\section{Errors in Clinical Judgment}

\section{Illusory Correlation}

There have been many studies documenting clinical judgment errors in the field of clinical psychology (e.g., Garb, 1989). One of the most well documented errors in clinical judgment involves basing decisions on illusory correlations (Chapman \& Chapman, 1967). An illusory correlation is the belief that a symptom or sign is predictive of a diagnosis or outcome when, in fact, no such relationship exists. An example of an illusory correlation is the false association that large eyes on human figure drawings indicate suspicious tendencies. Illusory correlations such as this are based on prior associations. These associations may warp perceptions so much that a relationship is believed to exist even when the true relation between a sign and a feature is inverse (Arkes, 1981). Clearly, to maximize accuracy, decisions ought not to be influenced by illusory correlations.

\section{Base-rate Fallacy}

Insensitivity to base rates, that is, the base-rate fallacy, is another well recognized, albeit less well documented, clinical judgement error. Base rates refer to the prevalence of a specific trait in a sample. An example of a base rate might be that $60 \%$ of residents living in a specific geographic area develop some form of cancer. This 
would be important information for a physician practicing in this area to have for diagnosing and treating medical problems. Research has shown, however, that when presented with this kind of information, people often ignore it or use it incorrectly (Kahneman \& Tversky, 1974). In contrast to illusory correlations, to maximize accuracy, decisions ought to be influenced by base rates.

\section{Clinical Judgment and School Psychology}

Despite the many studies documenting clinical judgment errors in the field of clinical psychology, there is a paucity of decision-making research in the field of school psychology. Fagley (1988) expressed a need for research about the decison-making errors of school psychologists. He argued that school psychologists often make assessment and judgement decisions under uncertainity, which possibly could lead to biased decision-making strategies.

O'Reilley, Northcraft, and Sabers (1989) conducted a study investigating the influence of referral questions on assessment and placement decisions. They suggested that the high special-education placement-to-referral ratio may result from a confirmation bias set into motion by a teacher's referral. This hypothesis was supported in their investigation. The results indicated that the weighting and recall of assessment data in the report and classification decisions were biased by the referral question. For example, if the referral question was to determine the presence of a learning disability, school psychologists were more likely to be influnced by and to remember data that supported that diagnosis. School psychologists also preferentially gathered data that corresponded to and supported the referral question and often failed to recognize disconfirming evidence.

Barnett (1988) warned that decisions made using instruments with adequate psychometric characteristics did not necessarily lead to sound decisions. Studies have suggested that although school psychologists usually are aware of the reliabilities of individual assessment techniques, they often are unaware of the validity of the 
diagnositic or classification decisions that result from the use of those techniques. For example, school psychologists have been shown to make errors in classifying children as learning disabled (Algozzine \& Ysseldyke, 1986; Macmann \& Barnett, 1985), and an observational study of MDTs suggested that there was little relationship between data presented at meetings and decisions that were reached (Ysseldyke, Algozzine, Richey, \& Graden, 1982).

These studies illustrate some of the kinds of decision-making investigations that have been reported to date in the field of school psychology. No studies have yet been reported that have examined potential differential susceptibilities to clinical judgment errors for MDTs versus individuals.

\section{Hypotheses}

As noted, a primary rationale behind the MDT model is that having a team of individuals should reduce the likelihood of biased decisions or errors in judgment. Therefore, this study examined if teams were more likely than individuals to use relevant base-rate information in their classification decisions. Moreover, this study also investigated if individuals were more likely than teams to use irrelevant illusorycorreltation information in their classisfication decisions. The following null hypotheses were investigated:

1. There will be no differences between team and individual placement decisions.

2. Tearns will not be any more likely to incorporate relevant base-rate information into their decisions than individuals.

3. Teams will not be any less likely to incorporate irrelevant illusorycorrelation information into their decisions than individuals. 


\section{METHOD}

\section{Subjects}

Participants were members of 20 multidisciplinary teams in Rhode Island and neighboring areas in Connecticut and Massachusetts. Teams were contacted in the following manner: School psychologists, selected from a listing available through the Rhode Island School Psychologists Association, were contacted by phone. They were asked to request that members from one of their multidisciplinary teams participate in the study. For some teams, directors of special education were contacted by phone from a Rhode Island listing and asked if one of their teams would participate. A total of 32 teams was contacted in this manner; 12 declined to participate because of time constraints. Of the participating teams, 13 were from Rhode Island, 4 from Connecticut, and 3 from Massachusetts.

Each team consisted of a school psychologist, an administrator, and a specialeducation diagnostician. Among the school psychologists who participated in the study (12 females, 8 males), the mean number of years of experience was 16.0 (range $=1$ to $32, \underline{\mathrm{SD}}=8.3$ ). The mean numbers of years on their team was 7.3 (range $=1$ to 22 , $\underline{\mathrm{SD}}$ $=7.6$ ). All of the school psychologists were certified in their respective states; 6 held a doctoral degree, 8 held a certificated of advanced graduate study (master's degree plus 30 additional graduate semester hours of credit), and 6 held a master's degree.

Among the special-education diagnosticians who participated in the study ( 3 males, 17 females), the mean number of years of experience was 13.8 ( range $=1$ to $32, \underline{\underline{S D}}=8.3$ ). The mean number of years on their team was 5.5 (range $=1$ to $18, \underline{S D}=$ 5.0). All of the diagnosticians were certified in their respective states; 5 held a master's degree plus 30 additional graduate semester hours of credit, 10 held a master's degree, and 5 held a bachelor's degree. 
Among the administrators who participated in the study (12 females, 8 males), the mean number of years of experience was 13.4 (range $=1$ to $26, \underline{S D}=7.0$ ). The mean number of years on their team was 3.3 ( range $=1$ to $12, \underline{S D}=2.8$ ). All of the administrators were certified in their respective states; 4 held a doctoral degree, 10 held a master's degree plus 30 additional graduate semester hours of credit, and 6 held a master's degree.

\section{$\underline{\text { Case Materials }}$}

The cases were based on actual psychoeducational evaluations conducted in a public school, but some test data and category information were added by the investigator based on his training and experience. Each case comprised data that included 16 categories selected from two major textbooks on the psychological assessment of children (Sattler, 1988; Weaver, 1985): (a) referral, (b) family/social history and psychosocial stressors, (c) developmental history, (d) history of educational and other services, (e) prior evaluations, (f) teacher report, (g) parent report, (h) clinician's observations, (i) Revised Child Behavior Profile, (j) Vineland Adaptive Behavior Scale, (k) projective results, (I) Wechsler Intelligence Scale for Children--Third Edition (WISC-III), (m) Developmental Test of Visual-Motor Integration, (n) Peabody Picture Vocabulary Test--Revised, (o) Woodcock-Johnson Psychoeducational Battery, and (p) Abbreviated Conners Teacher Rating Scale.

One of the cases (Case A) was designed to investigate susceptibility to illusory correlation. For this case, testing information suggested the possibility of a learning problem. Two different WISC-III profiles were used with this case. The IQ and factor scores were the same for both profiles, but the profiles differed in that one had a 3point intersubtest scatter (Case $A_{1}$ ) whereas the other had a 13-point intersubtest scatter (Case $\mathrm{A}_{2}$ ).

The other case (Case B) was designed to investigate the effects of providing base rate information on judgment. For this case, historical, teacher-report, and 
observational information suggested the possibility of an attentional problem. Two pieces of base-rate information were associated with this case. One piece stated an $80 \%$ incidence of Attention-defifict Hyperactivity Disorder (ADHD) in the population from which it was drawn (Case $B_{1}$ ), whereas the other piece stated a $20 \%$ incidence of ADHD (Case $B_{2}$ ). Cases $A_{1}, A_{2}, B_{1}, B_{2}$, appear in Appendix $A$.

\section{Procedure}

Participants were provided with the case information and a response sheet that included a list of ten diagnoses. These diagnoses were based on Rhode Island specialeducation regulations and included the following: (a) Speech/Language Impaired (S/L), (b) Learning Disabled (LD), (c) Visually Impaired (VI), (d) Hearing Impaired (HI), (e) Mentally Retarded (MR), (f) Behavior Disordered (BD), (g) Other Health Impaired (Other), (h) Multi-handicapped (multi), (i) Attention-deficit Hyperactivity Disorder, (ADHD) and (j) Non Disabled (Normal).

At the beginning of each session, participants were given the following instructions: "I am interested in the differences between decisions made by teams versus decisions made by individuals. You will be given four cases. On two of the cases you will work as a team to make decisions, and on the other two cases you will make individual decisions. You are presented with a list of handicapping conditions (diagnoses) and from the information provided, you are to assign a probability as to the likelihood that the child has each handicapping condition. You must assign a probability to each handicapping condition. Non Disabled is also provided as an option. Next to each probability estimate, state your confidence in that estimate on a scale from 0 to 100,0 being not confident at all and 100 being extremely confident."

Participants also were provided with an educational placement scale based on the Rucker-Gable Educational Placement Scale (Pfeiffer \& Naglieri, 1983). This placement scale appears in Appendix B. It included seven placements ranging from the least 
restrictive to the most restrictive environment. Participants were asked to select a placement after they had completed their probability and confidence estimates.

After participants had completed their initial probability, confidence, and placement responses they were asked to make the decisions again. Depending on the condition, either the WISC-III protocol or the base-rate information was altered. It was explained to the participants that this change might or might not alter their original decisions. They were asked to mark any changes on a second response sheet. The same procedure was followed when the participants worked as a team to assign the probabilities, confidence estimates, and placements.

At the end of the procedure, the participants were asked to rate the representativeness of the cases and to make a comparison of the amount of information provided with the amount of information that they usually had in a team meeting. Participants also were asked to rate if the team discussions were helpful and if they altered any of their decisions. All participants were treated in accordance with the ethical principles of the American Psychological Association (APA, 1989) and were debriefed properly on completion of the study.

\section{Design}

The study comprised three dependent variables and three independent variables. The dependent variables were: (a) placement-scale score, which potentially ranged from 1 to 7 , (b) probability for each of ten specified diagnoses, which potentially ranged from 0 to 100 , and (c) confidence rating for each of the ten probability ratings, which also potentially ranged from 0 to 100 . The independent variables were: (a) decision, that is, group and individual, (b) base rate, that is, lower (Case $B_{2}$ ) and higher (Case $\left.B_{1}\right),(c)$ intersubtest scatter, that is, lower (Case $A_{1}$ ) and higher (Case $A_{2}$ ), and (d) diagnosis, that is, S/L, LD, VI, HI, MR, BD, Other, Multi, ADHD, and Normal. The latter three independent variables were treated as repeated measures. 
Four designs were used with different combinations of the dependent and independent variables. The first design was of the form $\underline{A} \times(\underline{B} \times \underline{S})$, where $\underline{A}=$ decision (two levels: group vs. individual), $\underline{\mathrm{B}}=$ base rate (two levels: lower vs. higher), and $\underline{\mathrm{n}}=$ 10 measures in each of the $\underline{a}=2$ independent groups. The second design also was of the form $\underline{A} \times(\underline{B} \times \underline{S})$, where $\underline{A}=$ decision (two levels: group vs. individual), $\underline{B}=$ scatter (two levels: lower vs. higher), and $\underline{\underline{n}}=10$ measures in each of the $\underline{\mathrm{a}}=2$ independent groups. For both of these designs, placement-scale score served as a (univariate) dependent variable.

The third design was of the form $\underline{A} \times(\underline{B} \times \underline{\mathrm{C}} \times \underline{\mathrm{S}}$ ), where $\underline{\mathrm{A}}=$ decision (two levels: group vs. individual), $\underline{\mathrm{B}}=$ base rate (two levels: lower vs. higher), $\underline{\mathrm{C}}=$ diagnosis (ten levels: $S / L$ vs. LD vs. VI vs. HI vs. MR vs. BD vs. Other vs. Multi vs. ADHD vs. Normal), and $\underline{n}=10$ measures in each of the $\underline{a}=2$ independent groups. The fourth design also was of the form $\underline{\mathrm{A}} \times(\underline{\mathrm{B}} \times \underline{\mathrm{C}} \times \underline{\mathrm{S}})$, where $\underline{\mathrm{A}}=$ decision (two levels: group vs. individual), $\underline{\mathrm{B}}=$ scatter (two levels: lower vs. higher), $\underline{\mathrm{C}}=$ diagnosis (ten levels: $\mathrm{S} / \mathrm{L}$ vs. $L D$ vs. $\mathrm{VI}$ vs. $H I$ vs. MR vs. $B D$ vs. Other vs. Multi vs. $A D H D$ vs. Normal), and $\underline{n}=10$ measures in each of the $\underline{a}=2$ independent groups. For both of these designs, probability and confidence rating served as two (multivariate) dependent variables.

Each participant made decisions on each of the four cases, (i.e., Cases $A_{1}, A_{2}, B_{1}$, $B_{2}$ ); two of these decisions (i.e., either both cases $A_{1}$ and $A_{2}$ or both cases $B_{1}$ and $B_{2}$ ) were made individually, whereas the other two were made as members of three-person multidisicplinary teams. Thus, 30 participants (i.e., 10 school psychologists, 10 special-education diagnosticians, and 10 school administrators) completed Cases $\mathrm{A}_{1}$ and $A_{2}$ individually and Cases $B_{1}$ and $B_{2}$ as members of three-person multidisciplinary teams; the other 30 participants completed Cases $B_{1}$ and $B_{2}$ individually, and Cases $A_{1}$ and $A_{2}$ as members of multidisicplinary teams. Case order (i.e., $A_{1}-A_{2}$ vs. $A_{2}-A_{1}$; $B_{1}--B_{2}$ vs. $B_{2}--B_{1}$ ) and decision order (i.e., group--individual vs. individual-- 
group) were counterbalanced. Thus, presentation order for both case and decision were counterbalanced, and recorded by the investigator. 


\section{RESULTS}

The results of this investigation are reported in the following manner: First, measures used to assess the validity of the case scenarios are described. Second, the procedure for correcting for error that might occur when comparing team and individual decisions is described. Third, the results of the analyses involving the placement scale for the base-rate and scatter conditions are reported. Finally, the results of the analyses involving the probability and confidence ratings for the base-rate and scatter conditions are reported.

\section{Perceived Validity of the Case Scenarios}

Estimates comparing the amount of information received in each case scenario with the amount of information usually available ranged from $20 \%$ to $100 \%$ for the educational diagnosticians $(\underline{M}=70, \underline{S D}=20.3), 70 \%$ to $100 \%$ for the school psychologists $(\underline{M}=78, \underline{S D}=10.2)$, and $50 \%$ to $150 \%$ for the administrators $(\underline{M}=82$, $\underline{\mathrm{SD}}=23.8)$.

Participants were also asked how frequently they reviewed cases similar to the ones that were presented in this study. The choices were "often", "sometimes", or "rarely." For the two cases used to investigate the influence of intersubtest scatter (i.e., Case A), the responses were the following: (a) educational diagnosticians--60\% "often", $40 \%$ "sometimes"; (b) school psychologists--70\% "often", 30\% "sometimes"; and (c) administrators--80\% "often", 15\% "sometimes", 5\% "rarely". For the two cases used to investigate the influence of base-rate information (i.e., Case B), the responses were the following: (a) educational diagnosticians--80\% "often", 20\% "sometimes"; (b) school psychologists--65\% "often" ,30\% "sometimes", 5\% "rarely"; and (c) administrators--70\% "often", 30\% "sometimes". 
Comparing individual responses to team responses can create a potential statistical problem. Because there were three times as many individuals as teams, there was likely to be much more variability among individual responses. To the extent that variability is related to psychometric error, individual responses, therefore, were likely to show more error than team responses as measurement artifact. In order to address this problem, individual responses were pooled so that they would be based on the same number of participants as team responses.

Pooling was accomplished in two ways: (a) a school psychologist, an educational diagnostician, and an administrator were selected randomly from different teams, and their individual responses were averaged (i.e., arithmetic mean). This was repeated 20 times to equal the number of teams. Each individual response was used only once, and the pooled set of scores remained consistent throughout the analyses. This method of pooling was referred to as "mixed groups." In the mixed groups members were only pooled with emebers who had received information in the same order. Alternatively, (b) each of the three members of a team's individual responses were averaged. For example, persons $A, B$, and $C$ served on a team and made a collective response. The same people also made individual responses for a different case; in this instance, the responses of persons $A, B$, and $\mathrm{C}$ were averaged. This method of pooling was referred to as "intact groups."

Placement-Scale Analyses

\section{Base-Rate Conditions}

Two 2 (group and individual decision) by 2 (lower and higher base rate) univariate analyses of variance (ANOVAs), that is, the $\underline{A} \times(\underline{B} \times \underline{S})$ designs, were 
conducted for the dependent measure, placement-scale score. One of these ANOVAs was conducted for the mixed-groups method of pooling individual responses, whereas the other was conducted for the intact method.

Mixed groups. For mixed groups, neither of the main effects nor the interaction between these two sources of variation were significant $(\mathrm{D}>.20$ in all cases). The ANOVA table for this analysis is presented in Table 1.

\section{Insert Table 1 here}

In order to assess homogeneity of variance across conditions, Fmax statistics were calculated. For teams versus individuals, results of this analysis indicated that individual responses $(\underline{\mathrm{SD}}=.34$ ) had significantly less variability that team responses $(\underline{\mathrm{SD}}=.85)\left(\underline{F_{\max }}=6.2, \underline{\mathrm{D}}<.05\right)$. For higher $(\underline{\mathrm{S} D}=.67)$ versus lower $(\underline{\mathrm{SD}}=.63)$ base rates, results of this analysis indicated no differences in variability ( Fmax $_{\max }=1.1$, $\mathrm{p}>.05)$.

Intact groups. The ANOVA results for the intact-groups method of pooling individual responses were similar to the mixed-groups method, and these results are presented in Table 2.

Insert Table 2 here

The $\underline{F}_{\max }$ statistics again showed that individual responses $(\underline{\mathrm{SD}}=.48)$ had significantly less variability than team responses $(\underline{\mathrm{SD}}=.85)\left(\underline{E}_{\max }=3.1, \underline{\mathrm{p}}<.05\right)$ and that, for higher $(\underline{S D}=.73)$ versus lower $(\underline{S D}=.63$ ) base rates, there were no differences in variability $\left(\boldsymbol{F}_{\max }=1.2, \underline{p}>.05\right)$. 


\section{$\underline{\text { Scatter Conditions }}$}

Similar to the base-rate conditions, two 2 (group and individual decision) by 2 (lower and higher levels of intersubtest scatter) ANOVAs, that is, the $\underline{A} \times(\underline{B} \times \underline{S})$ designs, were conducted for the dependent measure, placement-scale score. Again, one of these ANOVAs was conducted for the mixed-groups method of pooling individual responses, whereas the other was conducted for the intact method.

Mixed groups. For mixed groups, the main effects for both decision and scatter were significant $(\underline{p}<.05)$ but the interaction between these sources of variation was not significant $(\mathrm{p}>.50)$. The ANOVA table for this analysis is presented in Table 3 . The main effect for decision revealed that the placement decision for teams $(\underline{M}=4.05)$ was more restrictive than the placement decision for individuals $(\underline{M}=3.58)$. The main effect for scatter revealed that the placement decision in the higher-scatter conditions $(\underline{M}=4.02)$ was more restrictive than the placement decision in the lower-scatter conditions $(\underline{M}=3.61)$.

Insert Table 3 here

Again, in order to assess homogeneity of variance across conditions, $\underline{F}_{\max }$ statistics were calculated. For teams versus individuals, results of this analysis indicated no difference in variability between individual responses $(\underline{S D}=.42)$ and team responses $(\underline{\mathrm{SD}}=.68)\left(\underline{\mathrm{F}}_{\max }=2.7, \underline{\mathrm{D}}>.05\right)$. For higher $(\underline{\mathrm{SD}}=.60)$ versus lower $(\underline{\mathrm{S} D}$ $=.54)$ scatter, results also indicated no differences in variability $\left(\boldsymbol{E}_{\max }=1.2, \mathrm{p}>\right.$ $.05)$.

Intact groups. The ANOVA results for the intact-groups method of pooling individual responses were similar to the mixed-groups method, and these results are presented in Table 4. The main effect for decision revealed that the placement decision for teams $(\underline{M}=4.05)$ was more restrictive than the placement decision for individuals 
$(\underline{M}=3.55)$. The main effect for scatter revealed that the placement decision in the higher-scatter conditions $(\underline{M}=4.02)$ was more restrictive than the placement decision in the lower-scatter conditions $(\underline{M}=3.61)$.

Insert Table 4 here

Again, in order to assess homogeneity of variance across conditions, Emax statistics were calculated. For teams versus individuals, results of this analysis indicated no difference in variability between individual responses $(\underline{S D}=.47)$ and team responses $(\underline{S D}=.68)\left(E_{\max }=2.1, \underline{D}>.05\right)$. For higher $(\underline{\mathrm{SD}}=.65)$ versus lower $(\underline{\mathrm{SD}}$ $=.68)$ scatter, results also indicated no differences in variability $\left(\underline{E}_{\max }=1.3, \mathrm{p}>\right.$ $.05)$.

Probability and Confidence Analyses

\section{Base-Rate Conditions}

Two 2 (group and individual decision) by 2 (lower and higher base rate) by 10 (diagnosis: S/L, LD, VI, HI, MR, BD, Other, Multi, ADHD, Normal) multivariate analyses of variance (MANOVAs), that is, the $\underline{A} \times(\underline{B} \times \underline{C} \times \underline{S}$ ) designs, were conducted for the dependent measures, probability and confidence rating. One of these MANOVAs was conducted for the mixed-groups method of pooling individual responses, whereas the other was conducted for the intact method.

Mixed groups. For mixed groups, the MANOVA main effect for diagnosis was significant, $E(18,322)=20.58, \underline{p}<: 01$, but neither of other two main effects nor any of the four interactions were significant. That is, for decision, $\mathrm{E}<1$; for base rate, $E(2,17)=1.23, \underline{p}>.30$; for base rate by decision, $E<1$; for diagnosis by decision, $\underline{E}$ 
$(18,322)=1.01, \underline{p}>.40$; for base rate by diagnosis, $\underline{F}<1$; and for base rate by diagnosis by decision, $\mathrm{E}<1$.

To investigate further the significant MANOVA main effect for diagnosis, separate univariate ANOVAs were conducted for each of the dependent variables. These results, which are presented in Tables 5 and 6 , showed that both probability and confidence contributed to the MANOVA main effect. All sources of variation involving the independent variable, diagnosis, were adjusted (Greenhouse \& Geisser, 1959), and these adjusted values are reported here. For probability, ANOVA results revealed a significant main effect for diagnosis, $E(3.32,59.83)=51.77, \underline{p}<.01$. For confidence, results also revealed a significant main effect for diagnosis, $\underline{E}(3.32,59.83)=5.29, \underline{p}<.01$. None of the other main effects or intractions were significant in these analyses $(\underline{p}>.10$ in all cases).

Insert Tables 5 and 6 here

To investigate further the significant ANOVA main effects for diagnosis, Tukey post hoc comparisons were conducted for each of the dependent variables across the ten levels of diagnosis. Given the large number of comparisions made, an alpha level (i.e., probability of type-1 error) of .01 was adopted for these analyses. Table 7 presents differences among mean probability ratings according to diagnosis. These results showed that the ADHD probability ratings $(\underline{M}=85.2$ ) were significantly higher than all other diagnoses. $B D(\underline{M}=45.6)$ and Normal $(\underline{M}=34.4)$ also were significantly higher than several other disability diagnoses. In general, the probability ratings of the remaining diagnoses were not significantly different from each other.

Insert Table 7 here 
Table 8 presents differences among mean confidence ratings according to diagnosis. These results esentially showed that participants were more confident of their MR diagnoses $(\underline{M}=99.5)$ than of their BD diagnoses $(\underline{M}=79.1)$.

Insert Table 8 here

Intact groups. Similar to the mixed-groups analysis, for intact groups, the MANOVA main effect for diagnosis was significant, $\underline{E}(18,322)=19.42$, $\underline{0}<.01$, but neither of other two main effects nor any of the four interactions were significant. That is, for decision, $\underline{E}<1$; for base rate, $E(2,17)=2.07, \underline{p}>.15$; for base rate by decision, $\underline{E}<1$; for diagnosis by decision, $\underline{E}(18,322)=2.18, \underline{p}>.35$; for base rate by diagnosis, $\underline{E}<1$; and for base rate by diagnosis by decision, $\underline{E}<1$.

Again, to investigate further the significant MANOVA main effect for diagnosis, separate univariate ANOVAs were conducted for each of the dependent variables. These results (with Geisser-Greenhouse adjustments), which are presented in Tables 9 and 10, showed that both probability and confidence contributed to the MANOVA main effect. For probability, ANOVA results revealed a significant main effect for diagnosis, $E$ ( 3.32 , $59.83)=46.33, \underline{\underline{Q}}<.01$. For confidence, results also revealed a significant main effect for diagnosis, $E(3.32,59.83)=5.50, \underline{\mathrm{g}}<.01$. None of the other main effects or intractions were significant in these analyses ( $\underline{p}>.10$ in all cases).

Insert Tables 9 and 10 here

Again, to investigate further the significant ANOVA main effects for diagnosis, Tukey post hoc comparisons $(\alpha=.01)$ were conducted for each of the dependent variables across the ten levels of diagnosis. Table 11 presents differences among mean probability ratings according to diagnosis. These results showed that the ADHD probability ratings 
$(\underline{M}=84.8)$ were significantly higher than all other diagnoses. $B D(\underline{M}=44.4)$ and Normal $(\underline{M}=35.7$ ) also were significantly higher than several other disability diagnoses. In general, the probability ratings of the remaining diagnoses were not significantly different from each other.

Insert Table 11 here

Table 12 presents differences among mean confidence ratings according to diagnosis. These results esentially showed that participants were more confident of their $M R$ diagnoses $(\underline{M}=99.5)$ than of their $B D$ diagnoses $(\underline{M}=78.5)$.

Insert Table 12 here

\section{Scatter Conditions}

Two 2 (group and individual decision) by 2 (lower and higher intersubtest scatter) by 10 (diagnosis: S/L, LD, VI, HI, MR, BD, Other, Multi, ADHD, Normal) MANOVA, that is, the $\underline{A} \times(\underline{B} \times \underline{C} \times \underline{S})$ designs, were conducted for the dependent measures, probability and confidence rating. Similar to the base-rate conditions analyses, one of these MANOVAs was conducted for the mixed-groups method of pooling individual responses, whereas the other was conducted for the intact method.

Mixed groups. For mixed groups, the main effects for decision, $\underline{E}(2,17)=$ $15.12, \underline{p}<.01$, and for diagnosis, $\underline{E}(18,322)=23.92, \underline{p}<.01$, were significant, but the main effect for scatter was not significant, $E(2,17)=2.65, \underline{p}>.05$. The diagnosis by decision interaction, $E(18,322)=2.49, \mathrm{p}<.01$; the diagnosis by scatter interaction, $E(18,322)=2.29, \underline{p}<.01$; and the diagnosis by decision by scatter

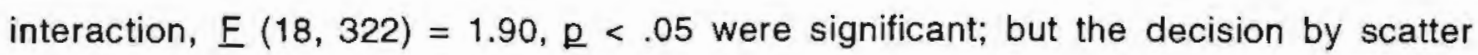
interaction was not significant, $E(2,17)=2.98, \mathrm{p}>.05$. 
To investigate further the significant MANOVA effects, separate univariate ANOVAs were conducted for each of the dependent variables. The ANOVA results for probability are presented in Table 13. Again, all sources of variation involving the independent variable, diagnosis, were adjusted (Greenhouse \& Geisser, 1959), and these adjusted values are reported here. Results revealed significant main effects for scatter, $\underline{E}(1,18)=5.57, \underline{p}<.05$, and for diagnosis, $\underline{E}(3.13,56.34)=61.18, \underline{p}<.01$. Results also revealed significant interactions for diagnosis by decision, $\underline{F}(3.13,56.34)=$ 3.36, $\mathrm{p}<.05$, and for scatter by diagnosis, $\underline{E}(3.51,63.22)=3.78, \underline{p}<.05$. None of the other main effects or intractions were significant in this analyses $(\underline{D}>.15$ in all cases).

Insert Table 13 here

To investigate further the two significant interactions, main-effects analyses were conducted. For the diagnosis-by-decision interaction, mean team versus individual decisons were compared for each of the ten diagnoses. These results are presented in Table 14. Here, for the normal diagnosis, individuals $(\underline{M}=18.6)$ reported significantly higher probability ratings than teams $(\underline{M}=2.5), \underline{\underline{p}}<.01$. Similarly, for the ADHD diagnosis, individuals $(\underline{M}=27.4$ ) reported significantly higher probability ratings than teams $(\underline{M}=5.7), p<.01$. There were no other significant differences between individuals and teams for any of the other eight diagnoses, $\underline{p}>.05$ in all cases.

Insert Table 14 here

For the scatter-by-diagnosis interaction, lower versus higher levels of scatter were compared for each of the ten diagnoses. These results are presented in Table 15. Here, for the normal diagnosis, the mean probability rating reported for the lower- 
scatter conditions $(\underline{M}=13.74)$ was significantly higher than that reported for the higher-scatter conditions $(\underline{M}=7.37), \underline{p}=.01$. In contrast, for the LD diagnosis, the mean probability rating reported for the lower-scatter conditions $(\underline{M}=51.86$ ) was significantly lower than that reported for the higher-scatter conditions $(\underline{M}=73.04)$, $\mathrm{p}$ $=.01$. There were no other significant differences between lower and higher scatter for any of the other eight diagnoses, $\mathrm{p}>.15$ in all cases.

Insert Table 15 here

Next, in investigating the significant MANOVA effects, a univariate ANOVA was conducted for confidence rating. These results are presented in Table 16. Again, adjusted values for all sources of variation involving the independent variable, diagnosis, are reported here. Results revealed significant main effects for decision, $\underline{E}$ $(1,18)=25.95, \underline{\mathrm{p}}<.01$, and for diagnosis, $\underline{E}(3.39,60.95)=5.53, \mathrm{~g}<.01$. Results also revealed a significant interaction for scatter by decision, $\underline{E}(1,18)=6.15, \mathrm{~g}<.05$. Neither the other main effect nor any of the other interactions were significant $(\mathrm{D}>.05$ in all cases).

Insert Table 16 here

To investigate further the significant ANOVA main effect for diagnosis, Tukey post hoc comparisons $(\alpha=.01)$ were conducted for mean confidence ratings across the ten levels of diagnosis. These results are presented in Table 17. These results showed that the MR diagnosis $(\underline{M}=98.9)$ was significantly higher than that for the Hl diagnosis $(\underline{M}$ $=80.3)$. The remaining mean confidence ratings were not significantly different from each other. 
To investigate further the significant interaction, a main effects analyses was conducted. For the scatter-by-decision interaction, mean team versus individual responses were compared for each level of scatter. Here, for the higher-scatter conditions, individuals $(\underline{M}=83.7)$ reported significantly lower confidence ratings than teams $(\underline{M}=95.4), \underline{D}<.05$. For the lower scatter conditions, however, confidence ratings for individuals $(\underline{M}=84.6)$ versus teams $(\underline{M}=91.1)$ did not differ significantly, $\underline{p}>.05$.

Intact groups. For intact groups, the MANOVA main effects for decision, $\underline{E}(2$, $17)=11.09, \mathrm{p}<.01$, and for diagnosis, $\mathrm{E}(18,322)=23.15, \mathrm{p}<.001$, were significant, but the main effect for scatter was not significant, $E(2,17)=2.37, \underline{p}>$ .05. The diagnosis by decision interaction, $\mathrm{E}(18,322)=2.27, \mathrm{p}<.01$, and the scatter by diagnosis interaction, $E(18,322)=2.44, \mathrm{p}<.01$, were significant; but the scatter by decison interaction was not significant, $\mathrm{E}(2,17)=2.34, \mathrm{p}>.05$, and the scatter by diagnosis by decision interaction, $\mathrm{E}(18,322)=1.62, \mathrm{p}<.05$, were not significant.

To investigate further the significant MANOVA effects, separate univariate ANOVAs were conducted for each of the dependent variables. The ANOVA results for probability are presented in Table 18. As in previous analyses, adjusted values for all sources of variation involving the independent variable, diagnosis, are reported here. Results revealed significant main effects for diagnosis, $\mathrm{E}(3.29,59.85)=58.93, \underline{\mathrm{p}}<$ .001 . Results also revealed significant interactions for diagnosis by decison, $E(3.29$, $59.25)=3.14, \mathrm{D}<.05$, and for scatter by diagnosis, $\underline{E}(3.38,60.79)=4.34, \mathrm{p}<.01$. None of the other main effects or intractions were significant in this analyses $(\underline{p}>.05$ in all cases). 
To investigate further the two significant interactions, main effects analyses were conducted. For the diagnosis-by-decision interaction, mean team versus individual decisions were compared for each of the ten diagnoses. These results are presented in Table 19. Here, for the normal diagnosis, individuals $(\underline{M}=20.2)$ reported significantly higher probability ratings than teams $(\underline{M}=2.5), \underline{p}=.01$. Similarly, for the ADHD diagnosis, individuals $(\underline{M}=27.6)$ reported significantly higher probability ratings than teams $(\underline{M}=5.7), \underline{Q}=.01$. There were no other significant differences between individuals and teams for any of the other eight diagnoses, $\mathrm{p}>.05$ in all cases.

Insert Table 19 here

For the scatter-by-diagnosis interaction, lower versus higher levels of scatter were compared for each of the ten diagnoses. These results are presented in Table 20. Here, for the normal diagnosis, the mean probability rating reported for the lowerscatter conditions $(\underline{M}=15.1)$ was significantly higher than that reported for the higher-scatter conditions ( $\underline{M}=7.7), \underline{R}=.01$. In contrast, for the LD diagnosis, the mean probability rating reported for the lower-scatter conditions $(\underline{M}=52.5)$ was significantly lower than that reported for the higher-scatter conditions $(\underline{M}=74.0), Q=$ .01. There were no other significant differences between lower and higher scatter for any of the other eight diagnoses, $p>.15$ in all cases.

Insert Table 20 here 
Next, in investigating the significant MANOVA effects, a univariate ANOVA was conducted for confidence rating. These results are presented in Table 21. Again, adjusted values for all sources of variation involving the independent variable, diagnosis, are reported here. Results revealed significant main effects for decision, $\mathrm{F}$ $(1,18)=22.99, \mathrm{Q}<.001$, and for diagnosis, $\mathrm{E}(3.66,65.84)=5.25, \mathrm{p}<.01$. Results also revealed a significant interaction for scatter by decision, $\underline{F}(1,18)=4.76, \underline{p}<.05$. Neither the other main effect nor any of the other interactions were significant $(\underline{p}>.05$ in all cases).

Insert Table 21 here

To investigate further the significant ANOVA main effect for diagnosis, Tukey post hoc comparisons $(\alpha=.01)$ were conducted for mean confidence ratings across the ten leveis of diagnosis. These resuits are presented in Table 22. These resuits showed that the mean confidence rating for the $M R$ diagnosis $(\underline{M}=98.3)$ was significantly higher than that for the $\mathrm{HI}$ diagnosis $(\underline{\mathrm{M}}=80.5)$. The remaining mean confidence ratings were not significantly different from each other.

Insert Table 22 here

Finally, to investigate further the significant interaction, a main effects analyses was conducted. For the scatter-by-decision interaction, mean team versus individual responses were compared for each level of scatter. Here, for the higherscatter conditions, individuals $(\underline{M}=83.8$ ) reported significantly lower confidence ratings than teams $(\underline{M}=95.4), \underline{p}<.05$. For the lower-scatter condtions, however, confidence ratings for individuals $(\underline{M}=84.3)$ versus teams $(\underline{M}=91.1)$ did not differ significantly, $\mathrm{p}>.05$. 


\section{DISCUSSION}

\section{Validity of the Case Scenarios}

Most mental-health decision making studies use case scenarios rather than actual patients. Scenarios are presented in one of three forms. Participants either examine data, watch a videotape, or meet with a person who simulates a disorder. Although the use of scenarios in decision-making research results in reproducible and reliable information, questions have been raised about generalization (Elstein, 1976). Contrary to this criticism, however, there is no evidence that clinicians behave differently when presented with scenarios than they do in professional practice (Dawes, 1986). Scenarios provide reproducible, reliable information and scenarios effectively control many extraneous variables. Thus, scenarios continue to be the method of choice in research on diagnostic decision-making in the fields of medicine and mental health (Clavelle \& Turner, 1980; Gauron \& Dickinson, 1966; Kendell, 1973; Turner \& Kofoed, 1984).

In the present study, participants' responses to questions about case validity suggested that they had experience dealing with cases like the ones presented. The overall ratings of amount of information provided were relatively high across all three disciplines, and estimates showed that most of the participants felt that they had at least about the same amount of information that they usually have when making a diagnostic or placement decision. Moreover, participants reported that they frequently reviewed cases similar to the ones presented in this study. 
As described previously, two methods were used to pool individual responses (i.e., "mixed" and "intact"), Results showed that these two methods yielded nearly identical findings, attesting to the stability of these results. Thus, for discussion purposes, the two methods of pooling individuals are combined.

\section{Placement Scale}

\section{Base-rate Conditions}

The results of these analyses suggested that base-rate information did not influence either team or individual placement decisions. There were no significant differences in placement decisions between the lower and the higher base-rate conditions. Although base-rate information should have influenced decisions, neither teams nor individuals seemed to integrate this information into their placement decisions. Another interesting finding was that, for the base-rate conditions, individuals were more consistent than teams in their placement decisions. Given the relationship between internal consistency and error, a possible implication of this finding is that in some instances, teams may be less accurate in their decisions than individuals.

\section{Scatter Conditions}

The results of these analyses suggested that the degree of intersubtest scatter on the WISC-III influenced placement decisions, and that both teams and individuals were equally as likely to be influenced by scatter. In contrast to the base-rate conditions, information that should not have influenced decisions did, in fact, have a significant impact. Teams and individuals both used the scatter information in determining a special-education placement. In the higher-scatter conditions, both teams and 
individuals selected more restrictive special-education placements than in the lowerscatter conditions. It seems that participants viewed the higher degree of scatter as representative of needing more services.

The significant main effect for decision indicated that, for these cases, teams generally selected more restrictive placements than individuals. This finding is of interest, because the current educational regulations state that a child should be placed in as least restrictive an environment as possible, yet for these cases, teams selected the more restrictive environments, despite the irrelevance of the scatter information to diagnosis.

In contrast to the results in the base-rate conditions, there was no difference between teams and individuals in the consistency of their placement decisions. Similar to the base-rate conditions, however, there was no difference in consistency between the higher- and lower-scatter conditions.

Probability and Confidence Ratings

\section{Base-rate Conditions}

Similar to the findings involving the placement scale, the results of the analyses involving the probability and confidence ratings indicated that base-rate information did not influence decisions, and that neither teams nor individuals integrated this information into their decisions. Here again, information that ought to have influenced decisions did not. These results also indicate that insensitivity to base- rates appears to be a reliable finding, in that this information failed to influence not only educational placements, but also confidence and probability ratings of diagnoses as well.

The significant main effect for diagnosis for both the probability and confidence ratings suggests that the participants viewed the cases as more representative of certain diagnoses than others. Participants generally deemed these cases as most representative 
of a child with Attention-deficit Hyperactivity Disorder (ADHD). These results attest to the validity of the cases, as they were designed to suggest a diagnosis of ADHD, so that the cases corresponded with the base-rate information provided.

Participants' confidence ratings for these cases were generally not significantly different from each other, and eventhough the cases were designed to be suggestive of ADHD participants were not more confident of this diagnosis in comparison with other diagnoses. This indicates that the case was not overly suggestive of ADHD and that other diagnoses were considered as well. It is not surprising that participants were most confident in their probability ratings of Mental Retardation, becuase this diagnosis is more easily determined than the others.

\section{Scatter Conditions}

Similar to the findings involving the placement scale, the results involving confidence and probability ratings suggest that the degree of intersubtest scatter on the WISC-III influenced diagnostic decisions, and that both teams and individuals were equally as likely to be influenced by scatter. Here again, information that should not have influenced diagnostic decisions did, in fact, influence decisions. The results also indicated that the influence of scatter appears to be a reliable finding, in that this information affected not only educational placements, but also confidence and probability ratings of diagnoses as well.

For these cases, scatter influenced the probability ratings of two diagnoses: Learning Disabled and Non Disabled (Normal). In the higher-scatter condition, both teams and individuals assigned higher probability ratings for a diagnosis of Learning Disabled than in the lower-scatter condition. Participants deemed the higher degree of scatter as representative of a child with a learning disability. This belief also was reflected in participants ratings of a Non Disabled diagnosis. Participants generally assigned higher probability ratings for Non Disabled in the lower-scatter condition than in the higher-scatter condition. 
There were also significant differences between team and individual probability ratings for the diagnoses of Non Disabled and ADHD. Individuals generally assigned higher probability ratings for a Non Disabled diagnosis than teams. This finding appears to correspond with teams generally selecting more restrictive placements than individuals. Teams appear to be more likely to judge a child as having a disability than individuals. Yet for this case, individuals appeared to be more likely to give a specific diagnosis of ADHD than teams.

An additional finding was that in the higher-scatter condition, teams were generally more confident than individuals. This finding suggests that when there was a high level of scatter, teams felt more confident in their diagnoses than individuals. Because the team process allows input from all members this might allow teams to feel more confident in their decisions. During the study, many participants commented that they did not like making these decisions alone, and that they felt more comfortable making the decisions as a team.

\section{Interpretation of the Results}

The results of this study showed that the cases were perceived to be valid, and that the participants also had experience with cases like the ones presented in this study. The results also indicated that the two different methods for pooling individual responses yielded comparable findings and was reliable.

The same general conclusions can be drawn from the results of the placement scale analyses and the analyses involving the probability and confidence ratings. Neither group nor individual decisions were influenced by relevant base-rate information, but both were influenced by irrelevant illusory-correlation information. In other words, neither teams norindividuals were influenced by information that ought to have influenced their decisions, but both were influenced by information that ought not to 
have influenced their decisions. In this sense, teams were no more accurate than individuals for the diagnostic decision-making tasks administered.

As previously mentioned, school psychologists frequently make clinical judgments under circumstances of uncertainty; resulting strategies and decisions, therefore, may be biased. The purpose of the MDT is to safeguard against decisionmaking errors, thereby improving the accuracy of decisions. The resuls of this study suggest that team decisions are no more accurate than individual decisions. To further interpret the results of this study, factors associated with team process, salience of information, and the nature of the task, must be addressed.

Kaiser and Woodman (1985) suggested that there may be several variables that affect the team process, causing them to function suboptimally. These variables include issues about professional territoriality, role confusion, and lack of team-process training and experience. They also suggested that no single factor could account for the apparent suboptimal functioning of teams. Instead, this might be due to characteristics of team members and the dynamics of the team. Of course, it is likely that these same variables might interfere with MDT functioning.

An additional process variable influencing team performance appears to be poor participation among some teams members. Observational and survey studies of MDTs have indicated that some disciplines do not participate as much in the team meetings as other disciplines (Foster, Ysseldyke, Casey, \& Thurber,1984; Kabler \& Carton, 1981). Teachers are among those professionals listed as having minimal participation. There is some evidence that teachers are quite accurate in making judgments about the presence of learning disabilities (Gresham, Carey, \& Reschly, 1987). Teachers, therefore, are an important team resource, yet their paticipation is less than that of other team members.

Unequal participation by team members was also found in the research conducted in social and organizational psychology. Here, it was found that a sharing of resources 
only took place under particular conditions, such as when the most competent member of a group could not solve the problem, or when the level of ability among group members was mixed (Laughlin \& Blitz, 1975; Shaw \& Ashton, 1976). It is uncertain whether these conditions are present during a MDT meeting. Beacuse MDT members usually have comparable training and experience, they may not be likely to rely on, or to request input from, other team members.

The MDT format also might provide an environment that fosters overconfidence in diagnostic decisions. In the present study, mean confidence ratings in the diagnostic probability ratings generally were quite high for both individuals and teams. Teams, however, were significantly more confident of their diagnostic decisions than individuals in the higher-scatter conditions. Holsopple and Phelan (1954) have found that the most confident diagnosticians tend to be the least accurate. Treament effects sometimes contribute to overconfidence (Einhorn \& Hogarth, 1978). For example, if a team suggests a resource-room based intervention approach and the child subsequently shows improvement, the team might take this as evidence that the child was, in fact, learning disabled. The team might not consider that many non learning-disabled children also might show improved learning given this intervention. This also might explain why teams tended to be more restrictive in their educational placements than individuals in the present study. Teams might have a tendency to prescribe more treatment because children are more likely to show improvement when more services are provided. This, in turn, is likely to reinforce the MDT's perception of the success their team processs.

In addition to team process issues that might hinder performance, the difficulty of the team's task must be considered. The purpose of the MDT is to make appropriate diagnostic and placement decisions for special-education services. In some instances, special-educational diagnoses are defined ambiguously with no univiersally agreed upon criteria. Although the tests that are availabee to investigate eligibility for special- 
education services generally are reliable, no obtained score is error free. Given the tasks and the kind of information available to MDTs it seems that using a team format might not be the most effective strategy for improving accuracy.

Burns (1990) questioned the relevance of base-rate information for the clinical practices of school psychologists because "it offers little practical help in the many lowincidence type decisions with which they are confronted" (p. 361). As an example, Burns cited that a school psychologist, knowing that the incidence of teenage suicide attempts is relatively low, could be accurate most of the time in predicting that the adolescent will not attempt suicide. Such a strategy, although yielding accurate results most of the time, obviously would be disastrous on those occasions when an adolescent does, in fact, attempt suicide. Of course, understanding the relevance of base-rate information does not preclude an appropriate cost-benefit analysis of a clinical decision. Indeed, there will be circumstances when a clinicaian will want to error on the side of diagnosing a condition when it is likely not to be present (i.e., decide not to defer to base-rate information); this clearly is quite different from failing to understand the significance of base rates at all (i.e., the base-rate fallacy).

\section{Limitations}

There are some limitations to this study that should be considered when evaluating the findings. First, teams were compared to pooled sets of individuals. This study did not examine whether teams outperformed specific team members. The majority of the research in social and organizational psychology suggests that teams are more accurate than the average individual (Hill, 1982). It is unlikely, however, that any of the individual members of the teams could be considered average because they all had considerable training and experience. Thus, the question still remains as to whether teams would outperform individuals with considerable training and experience. The 
results of this study, however, did not indicate whether teams outperformed specific kinds of professionals (e.g., school psychologists, special educatators, administrators). Thus, this warrants further investiagtion.

A second limitation is that accuracy was specifically defined by susceptibility to clinical judgment errors (i.e., using illusory-correlation information and underutilization of base-rate information). There may be situations where MDTs make more accurate decisions than individuals when the task is different or accuracy is defined alternatively. More studies need to be conducted to determine under what circumstances teams might ouperform individuals.

A third limitation of this study was that it focued on the outcome of the team process rather than the team process per se. This study did not provide information about group interaction that could explain the relatively poor performance of the teams. Further study is needed to determine how team process factors affect accuracy, and to identify effective strategies that teams could adopt in order to improve decision-making accuracy.

\section{Conclusions and Implications}

Three major questions were investigated in this study: (a) Will there be any differences between team and individual placement decisions?, (b) Will teams be more likely to incorporate relevant base-rate information into their decisions than individuals?, and (c) Will teams be any less likely to incorporate irrelevent illusorycorrelation information into their decisions than individuals?.

First, results showed that there were no differences between team and individual decisions in the base-rate conditions but that there were differences in the scatter conditions. Teams were more likely to be more restrictive in their placements, when presented with data that should not have affected their decisions, but there was no 
difference when information that should be incorporated into decision-making was presented. Additionally, there was less variability in the base-rate conditions in the individual placements than in the team placements. Variability is related to error, and to the extent that there was more variability among the team decisions than the individual decisions, teams could potentially be less accurate than individuals. These findings suggest that teams are not any more accurate in their placement decisions than individuals, and in some instances the individuals outperformed the teams. These results are comparable to investigations conducted in social psychology where teams generally did not outperform pooled individuals on a variety of tasks (Faust, 1959; Harari \& Graham, 1975).

Second, both teams and individuals failed to incorporate base-rate information into their diagnostic and placement decisions. Insensitivity to base-rates is a documented error in clinical judgement (e.g., Kahneman and Tversky, 1977). The use of MDTs was based on the belief that the team process would guard against errors in decision-making. The results of this study, however, showed that teams were not any more likely than individuals to incorporate base-rate information into their decisionmaking. This result provides further support for research conducted in school psychology suggesting that teams are not functioning in the way that they were intended (Kabler \& Carton, 1981; Yoshida, Fenton, Maxwell \& Kaufman, 1978; Ysseldyke, Algozzine, \& Allen, 1981).

Third, teams were just as likely as individuals to be influenced by irrelevent information. Teams and individuals alike, falsely associated a higher degree of scatter as indicating a disability and, therefore, requiring a more restrictive learning environment. Basing decisions on illusory correlations is also a well documented error in clinical judgment (Chapman \& Chapman, 1969). As mentioned earlier, teams were established to guard against errors and thereby to improve accuracy. The results of this study suggest that team decisions are not more accurate than individual decisions. 
Thus, using a realistic task and teams that had considerable experience working together, this study did not support the belief that team process improves the accuracy of decisions that might be made by individuals acting alone. These results are similar to studies comparing teams and individuals in social and organizational psychology (Hill, 1982). Public Law 94-142, which requires special education eligibility decisions to be determined through a team format, continues to lack empirical support. Although studies have shown that teams generally outperform the average individual on certain cognitive tasks, other studies have shown that highly competent individuals perform as well or better than teams. The team process only appears to be useful when the individual lacks the skills or knowledge to solve the problem alone (Shaw \& Ashton, 1976).

A considerable amount of time and money is spent implementing the MDT process in our nation's school systems, yet there currently is no empirical support for using a team process for these decisions. Further research is needed to determine the reasons for the relatively poor performance of MDT's so that this process is improved. This research is crucial to the proper determination and delivery of special education services. It is important for MDT members to consider the practical impliations of these findings.

For example, it currently seems ill advised for professionals who serve on MDTs to feel more confident in MDT than individual decisions; there is no empirical evidence to support this assumption. These professionals should try to familiarize themselves with group dynamics that might adversely affect the accuracy of the team decisions. Here, MDT participants should explore whether different team members are sharing their knowledge and expertise during the meetings. This may be especially true for teacher input, because studies generally have shown low teacher participation in the MDT process, despite research showing that for some diagnositic decisions teachers are quite accurate. Finally, because clinicians, including school psychologists, often lack insight 
about how they use information when making a diagnostic decisions (Aspel, 1992;

Gauron \& Dickinson, 1969), MDT participants should try to consider the influence and validity of the information that they are using for their decisions, actively questioning the relationship between data and decision throughout the MDT process. 


\title{
APPENDIX A
}

\author{
Case $A_{1}$
}

\section{Referral}

Jeremy was referred by his mother at the suggestion of his teacher to investigate academic problems (primarily in reading). He is a 9 year, 5 month old white male who currently is in the third grade.

\section{Family/Social history and Psychosocial stressors}

Jeremy lives with his mother (age 32), a hairdresser; two brothers (ages 8 and 12); and his sister (age 10). His parents are divorced. Jeremy's father (age 31), a construction worker, sees the children weekly.

\section{Developmental History}

Jeremy was born on time subsequent to a normal pregnancy. There were no problems during the delivery. Jeremy weighed a little under eight pounds at birth, and there were no significant postnatal problems. Jeremy and his mother were released from the hospital after three days. He attained the usual developmental milestones within generally age-appropriate times. For example, he walked alone at 11 months and spoke short sentences at 21 months. His mother reported that he was an easy infant and toddler to care for, and that currently his health is good. There is no history of significant illnesses or injuries. He had tubes put in his ears at age three years. There are no visual or auditory problems.

\section{History of Educational and Other Services}

Jeremy attended kindergarten and currently is in a regular third grade classroom in a public school. He was retained in Grade 1. He currently is receiving some one to one instruction in reading from an aide two or three times a week for approximately half an hour.

\section{Prior Evaluations}

A speech and language assessment was conducted with Jeremy during this past month. The speech/language pathologist noted global receptive and expressive language delays, with particular difficulty in the comprehension of verbal instructions.

\section{Teacher Report}

Jeremy's teacher reported that he has difficulty concentrating and independently completing assignments. He interacts well with his classmates. She estimated his present levels in arithmetic, reading, and language as below average; but spelling, handwriting, social studies, science, and physical education as average.

\section{School Psychologist's Observations}

During the assessment, Jeremy presented as an attractive young man who demonstrated nicely developed attention skills for a child his age in a one-to-one interaction. Jeremy also talked himself through the tasks, which is usually characteristic of a much younger child. The school psychologist suspected that Jeremy may have some mild language-comprehension difficulties. For example, he confused the meanings of words such as "before" and "after." Jeremy remained pleasant and cooperative throughout the session.

During a classroom observation, Jeremy was frequently off task and disturbed other children while they were working. When the teacher was talking in front of the class, Jeremy was able to attend and to remain in his seat. 
Bevised Child Behavior Profile (Parent Version)

$\begin{array}{lc}\text { Behavior Problem } & \text { T Score }(M=50, S D=10) \\ \text { Total } & 60 \\ \text { Internalizing } & 59 \\ \text { Externalizing } & 62 \\ \text { Social Competence } & \\ \text { Total } & 24\end{array}$

Vineland Adaptive Behavior Scales, Interview Edition

$\begin{array}{lc}\text { Domain } & \text { Standard Score }(M=100, S D=15) \\ \text { Communication } & 75 \\ \text { Daily Living Skills } & 85 \\ \text { Socialization } & 78 \\ \text { Adaptive Behavior Composite } & 79\end{array}$

\section{Projective Results}

On a sentence completion, Jeremy expressed concerns about his performance in school. Jeremy is also concerned about parent and teacher approval.

Developmental Test of Visual-Motor Integration

Standard Score: $7(M=10, S D=3)$

Peabody Picture Vocabulary Test- Revised

Standard Score: $70 \quad(M=100, S D=15)$

Wechsler Intelligence Scale for Children - Third Editions (WISC-III)

Verbal_Subtest Scores $(M=10, S D=3)$

Information $=\quad 9$

Similarities $=9$

Arithmetic $=\quad 8$

Vocabulary $=\quad 7$

Comprehension $=\quad 8$

(Digit Span $=\quad 8$ )
Performance Subtest Scores ( $M=10, S D=3$ )

Picture Completion $=\quad 9$

Coding $=\quad 8$

Picture Arrangement $=10$

Object Assembly $=\quad 9$

Block Design $=\quad 10$

(Symbol Search $=\quad 9$ )

10 and Index Scores $(M=100, S D=15)$

Verbal

Performance

Full Scale

90

Verbal Comprehension

89

Percoptual-Organization

97

Freedom from Distractibility

90

Processing Speed

93

Woodcock-Johnson Psychoeducational Battery

Subject

Reading Cluster

Math Gluster

Written Language

Knowledge Cluster
Standard Score $(M=100, S D=15)$

72

76

74

90 


\section{Case $\mathrm{A}_{2}$}

\section{Referral}

Jeremy was referred by his mother at the suggestion of his teacher to investigate academic problems (primarily in reading). $\mathrm{He}$ is a 9 year, 5 month old white male who currently is in the third grade.

\section{Family/Social history and Psychosocial stressors}

Jeremy lives with his mother (age 32), a hairdresser; two brothers (ages 8 and 12); and his sister (age 10). His parents are divorced. Jeremy's father (age 31), a construction worker, sees the children weekly.

\section{Developmental History}

Jeremy was born on time subsequent to a normal pregnancy. There were no problems during the delivery. Jeremy weighed a little under eight pounds at birth, and there were no significant postnatal problems. Jeremy and his mother were released from the hospital after three days. He attained the usual developmental milestones within generally age-appropriate times. For example, he walked alone at 11 months and spoke short sentences at 21 months. His mother reported that he was an easy infant and toddler to care for, and that currently his health is good. There is no history of significant illnesses or injuries. He had tubes put in his ears at age three years. There are no visual or auditory problems.

\section{History of Educational and Other Services}

Jeremy attended kindergarten and currently is in a regular third grade classroom in a public school. He was retained in Grade 1. He currently is receiving some one to one instruction in reading from an aide two or three times a week for approximately half an hour.

\section{Prior Evaluations}

A speech and language assessment was conducted with Jeremy during this past month. The speech/language pathologist noted global receptive and expressive language delays, with particular difficulty in the comprehension of verbal instructions.

\section{Teacher Report}

Jeremy's teacher reported that he has difficulty concentrating and independently completing assignments. He interacts well with his classmates. She estimated his present leveis in arithmetic, reading, and language as below average; but spelling, handwriting, social studies, science, and physical education as average.

\section{School Psychologist's Observations}

During the assessment, Jeremy presented as an attractive young man who demonstrated nicely developed attention skills for a child his age in a one-to-one interaction. Jeremy also talked himself through the tasks, which is usually characteristic of a much younger child. The school psychologist suspected that Jeremy may have some mild language-comprehension difficulties. For example, he confused the meanings of words such as "before" and "after." Jeremy remained pleasant and cooperative throughout the session.

During a classroom observation, Jeremy was frequently off task and disturbed other children while they were working. When the teacher was talking in front of the class, Jeremy was able to attend and to remain in his seat. 
Revised Child Behavior Profile (Parent Version)

$\begin{array}{lc}\text { Behavior Problem } & \text { T Score }(M=50, S D=10) \\ \text { Total } & 60 \\ \text { Internalizing } & 59 \\ \text { Externalizing } & 62 \\ \text { Social Competence } & \\ \text { Total } & 24\end{array}$

Vineland Adaptive Behavior Scales, Interview Edition

$\begin{array}{lc}\text { Domain } & \text { Standard Score }(M=100, S D=15) \\ \text { Communication } & 75 \\ \text { Daily Living Skills } & 85 \\ \text { Socialization } & 78 \\ \text { Adaptive Behavior Composite } & 79\end{array}$

\section{Projective Results}

On a sentence completion, Jeremy expressed concerns about his performance in school. Jeremy is also concerned about parent and teacher approval

\section{Developmental Test of Visual-Motor Integration}

Standard Score: $7 \quad(M=10, S D=3)$

\section{Peabody Picture Vocabulary Test- Revised}

Stand ard Score: $70 \quad(M=100, S D=15)$

\section{Wechșler Intelligence Scale for Children - Third Editions (WISC-III)}

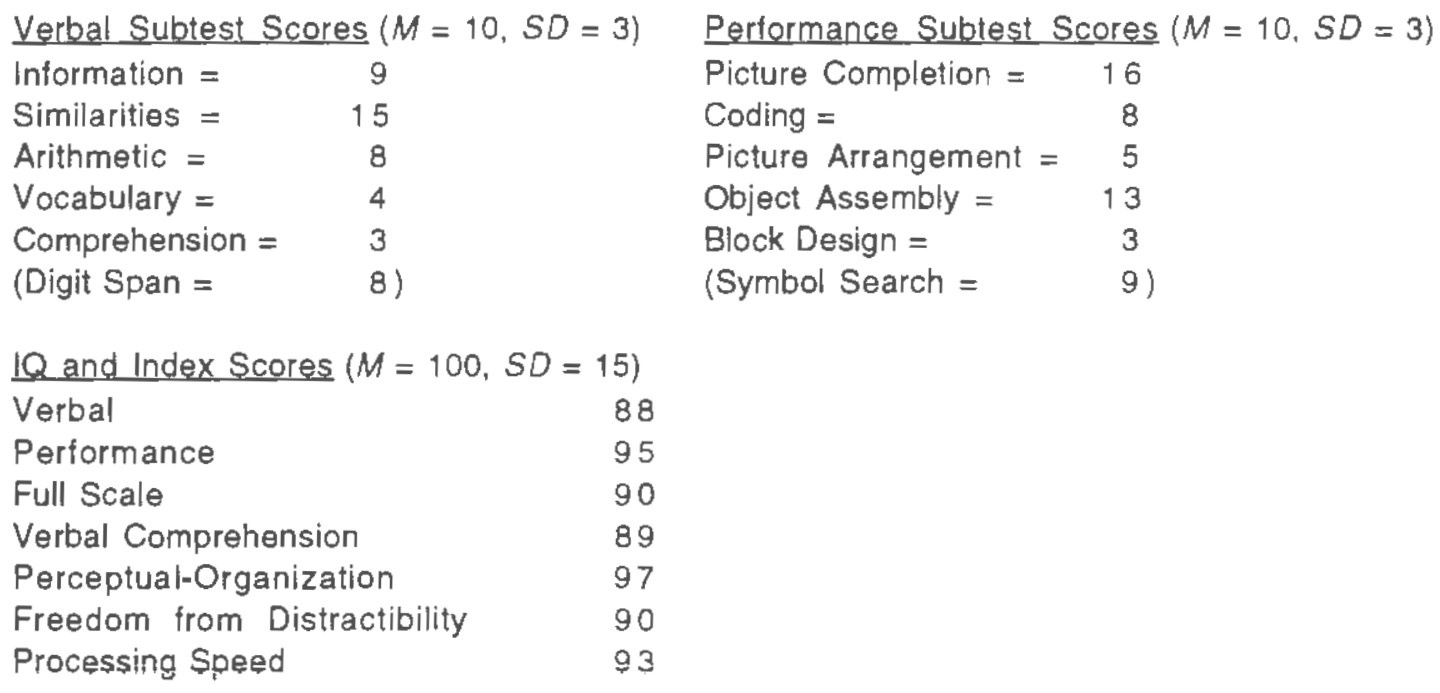

Woodcock-Johnson Psychoeducational Battery

$\begin{array}{lc}\text { Subject } & \text { Standard Score }(M=100, S D=15) \\ \text { Reading Cluster } & 72 \\ \text { Math Cluster } & 76 \\ \text { Written Language } & 74 \\ \text { Knowledge Cluster } & 90\end{array}$




\section{Case $B_{1}$}

\section{Referral}

Ernie was referred to the Multidisciplinary Team by his parents and an ADHD clinic at a local Hospital where he was evaluated. Ernie's parents and teacher are seeking a different placement due to his difficult to manage behavior in the classroom. Ernie, a 9year 2 month old boy is currently in a regular education third grade class.

\section{Family/Social History and Psychosocial stressors}

Ernie lives with his mother (age 34), a homemaker; his father (age 36), a salesman; and his sister (age 5). Ernie's mother reported that her marital relationship with her husband is good. Ernie's mother assumes most of the caretaking responsibilities for both children. Ernie's father usually spends time with him in the evenings heiping him with his homework. Ernie does not usually play with his sister, and the few times that he does he is usually mean to her (e.g., he breaks her toys).

\section{Developmental History}

Ernie was born on time subsequent to a normal pregnancy. There were no problems during the delivery. Ernie weighed a little over seven pounds at birth, and there were no significant postnatal problems. Ernie and his mother were released from the hospital after three days. He attained the usual developmental milestones within generally age-appropriate times. For example, he stood alone at 9 months and spoke short sentences at 25 months. His mother reported that he was a restless and demanding toddler who required little sleep. He currently is in good health. There is no history of any significant illnesses, injuries, or operations. There are no visual or auditory problems.

\section{History of Educational and Other Services}

Ernie was rejected by a private preschool program due to his difficult behavior. After a problematic year in kindergarten. Ernie was placed in a special behavioral program for firstand second-grade students. There was no follow-up on this suggestion and he now attends a regular classroom for most subjects, but spends a lot of time working individually with a teacher's aide

\section{Prior Evaluations}

Based on his school behavior, Ernie's current teacher suggested that he be evaluated for ADHD. His parents sought an outside evaluation and brought him to an ADHD clinic at a local hospital. Approximately $20 \%$ of the children referred to this clinic meet the criteria for ADHD. Ernie was diagnosed ADHD based on the results from the evaluation at this clinic.

\section{Teacher Report}

Ernie's teacher described him as restless and unable to concentrate. He is constantly out of his seat taiking to other children when they are working. Ernie has also become increasingly disobedient and defiant. He often refuses to do his work and occasionally talks back to the teacher. Ernie cannot work independently unless there is a teacher sitting right next to him. His teacher estimates that he is in the average range for reading, spelling, math, and science but that this is largely due to the individualized attention he receives from the aide.

\section{School Psychologist's Observations}

During the assessment, Ernie was able to perform the tasks that were asked of him, although he did need almost constant prompting to remain on task. His appearance was somewhat disheveled, and Ernie's attention span was quite short for a child his age. Ernie squirmed in his seat and frequently grabbed materials from the examiner's hands. Ernie's mood was quite pleasant but he was often not cooperative. Positive reinforcement and 
encouragement were used when Ernie started to become uncooperative and this strategy was very successful in getting him back on task.

During a classroom observation, Ernie was constantly out of his seat and was quite disruptive. The teacher had placed Ernie's desk right in front of her so that she could easily monitor him. Quite often, she needed to give him directions two or three times before he would respond. When the teacher was not watching him, he bothered other children while they were working. At this time he was sent to the principal's office, he initially refused but when she went to use the intercom he left the room and went to the office.

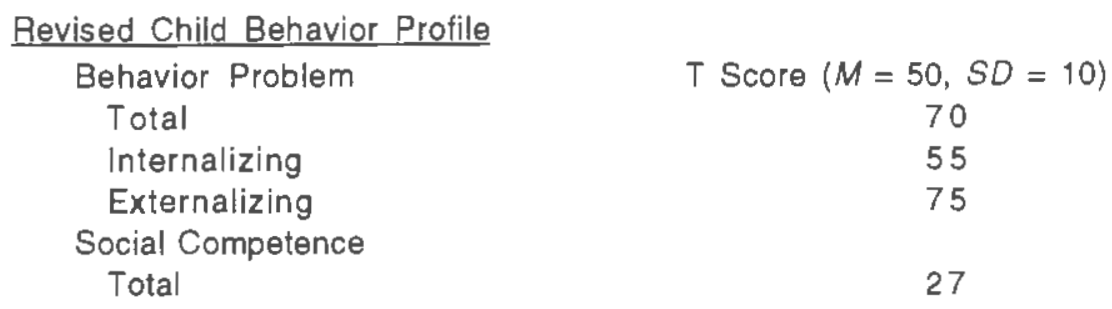

Vineland Adaptive Behavior Scales, Interview Edition

$\begin{array}{lc}\text { Domain } & \text { Standard Score }(M=100, S D=15) \\ \text { Communication } & 95 \\ \text { Daily Living Skills } & 90 \\ \text { Socialization } & 85 \\ \text { Adaptive Behavior Composite } & 86\end{array}$

\section{Projective Results}

On a sentence completion, Ernie had a recurrent theme of his teacher being mean and not liking him. Ernie also realizes that he is not usually nice to his sister and would like to change so that his mother was not so often angry with him. He also indicated that he often preferred to be alone, but that he wished he had more friends.

Developmental Test of Visual Motor Integration

Standard Score: $8(M=10, S D=3)$

Peabody Picture Vocabulary Test-Revised

Standard Score: $118 \quad(M=100, S D=15)$

Wechsier Intelligence Scale for Children. Third Editions (W/SC-1II)

Yerbal Subtest Scores $(M=10, S D=3)$

Information $=\quad 13$

Similarities $=\quad 13$

Arithmetic $=9$

Vocabulary $=13$

Comprehension $=12$

(Digit $\operatorname{Span}=\quad 8$ )
Pertormance Subtest Scores $(M=10, S D=3)$

Picture Completion $=9$

Coding $=\quad 13$

Picture Arrangement $=12$

Object Assembly = 8

Block Design $=\quad 12$

(Symbol Search $=\quad 10)$

$\angle \mathrm{Q}$ and Index Scores $(M=100, S D=15)$

Verbal

Performance

Full Scale 
Woodcock Johnson Psychoeducational Battery

Subject

Reading Cluster

Math Cluster

Written Language

Knowledge Cluster
Standard Score $(M=100, S D=15)$

107

110

105

115 


\section{Case $\mathrm{B}_{2}$}

\section{Referral}

Ernie was referred to the Multidisciplinary Team by his parents and an ADHD clinic at a local Hospital where he was evaluated. Ernie's parents and teacher are seeking a different placement due to his difficult to manage behavior in the classroom. Ernie, a gyear 2 month old boy is currently in a regular education third grade class.

\section{Eamily/Social History and Psychosocial stressors}

Ernie lives with his mother (age 34), a homemaker; his father (age 36), a salesman; and his sister (age 5). Ernie's mother reported that her marital relationship with her husband is good. Ernie's mother assumes most of the caretaking responsibilities for both children. Ernie's father usually spends time with him in the evenings helping him with his homework. Ernie does not usually play with his sister, and the few times that he does he is usually mean to her (e.g., he breaks her toys).

\section{Developmental History}

Ernie was born on time subsequent to a normal pregnancy. There were no problems during the delivery. Ernie weighed a little over seven pounds at birth, and there were no significant postnatal problems. Ernie and his mother were released from the hospital after three days. He attained the usual developmental milestones within generally age-appropriate times. For example, he stood alone at 9 months and spoke short sentences at 25 months. His mother reported that he was a restless and demanding toddler who required little sleep. He currently is in good health. There is no history of any significant illnesses, injuries, or operations. There are no visual or auditory problems.

\section{History of Educational and Other Services}

Ernie was rejected by a private preschool program due to his difficult behavior. After a problematic year in kindergarten, Ernie was placed in a special behavioral program for firstand second-grade students. There was no follow-up on this suggestion and he now attends a regular classroom for most subjects, but spends a lot of time working individually with a teacher's aide

\section{Prior Evaluations}

Based on his school behavior, Ernie's current teacher suggested that he be evaluated for ADHD. His parents sought an outside evaluation and brought him to an ADHD clinic at a local hospital. Approximately $80 \%$ of the children referred to this clinic meet the criteria for ADHD. Ernie was diagnosed ADHD based on the results from the evaluation at this clinic.

\section{Teacher Report}

Ernie's teacher described him as restless and unable to concentrate. He is constantly out of his seat talking to other children when they are working. Ernie has also become increasingly disobedient and defiant. He often refuses to do his work and occasionally talks back to the teacher. Ernie cannot work independently unless there is a teacher sitting right next to him. His teacher estimates that he is in the average range for reading, spelling, math, and science but that this is largely due to the individualized attention he receives from the aide.

\section{School Psychologist's Observations}

During the assessment, Ernie was able to perform the tasks that were asked of him, although he did need almost constant prompting to remain on task. His appearance was somewhat disheveled, and Ernie's attention span was quite short for a child his age. Ernie squirmed in his seat and frequently grabbed materials from the examiner's hands. Ernie's mood was quite pleasant but he was often not cooperative. Positive reinforcement and 
encouragement were used when Ernie started to become uncooperative and this strategy was very successful in getting him back on task.

During a classroom observation, Ernie was constantly out of his seat and was quite disruptive. The teacher had placed Ernie's desk right in front of her so that she could easily monitor him. Quite often, she needed to give him directions two or three times before he would respond. When the teacher was not watching him, he bothered other children while they were working. At this time he was sent to the principal's office, he initially refused but when she went to use the intercom he left the room and went to the office.

Revised Child Behavior Profile

$\begin{array}{lc}\text { Behavior Problem } & \text { T Score }(M=50, S O=10) \\ \text { Total } & 70 \\ \text { Internalizing } & 55 \\ \text { Externalizing } & 75 \\ \text { Social Competence } & \\ \quad \text { Total } & 27\end{array}$

Vineland Adaptive Behavior Scales, Interview Edition

$\begin{array}{lc}\text { Domain } & \text { Standard Score }(M=100, S D=15) \\ \text { Communication } & 95 \\ \text { Daily Living Skills } & 90 \\ \text { Socialization } & 85 \\ \text { Adaptive Behavior Composite } & 86\end{array}$

\section{Projective Results}

On a sentence completion, Ernie had a recurrent theme of his teacher being mean and not liking him. Ernie also realizes that he is not usually nice to his sister and would like to change so that his mother was not so often angry with him. He also indicated that he often preferred to be alone, but that he wished he had more friends.

\section{Developmental Test of Visual Motor Integration \\ Standard Score: $8(M=10, S D=3)$ \\ Peabody Picture Vocabulary Test-Pevised \\ Standard Score: $118 \quad(M=100, S D=15)$ \\ Wechsler Intelligence Scale for Children - Third Editions (WISC-I||)}

\begin{tabular}{|c|c|c|c|c|}
\hline Verbal Subtest S & s $(M=1$ & $=3)$ & Performance Subtest S & ores \\
\hline Information = & 13 & & Picture Completion = & 9 \\
\hline Similarities $=$ & 13 & & Coding $=$ & 13 \\
\hline Arithmetic $=$ & 9 & & Picture Arrangement $=$ & 12 \\
\hline Vocabulary $=$ & 13 & & Object Assembly = & 8 \\
\hline Comprehension = & 12 & & Block Design $=$ & 12 \\
\hline (Digit Span $=$ & 8) & & (Symbol Search $=$ & 10) \\
\hline $1 \mathrm{Q}$ and Index Sco & $(M=100$ & $15)$ & . & \\
\hline Verbal & & 112 & & \\
\hline Performance & & 106 & & \\
\hline Full Scale & & 109 & & \\
\hline Verbal Comprehen & & 116 & & \\
\hline Perceptual-Organ & tion & 102 & & \\
\hline Freedom from D & actibility & 93 & & \\
\hline
\end{tabular}


Woodcock Johnson Psychoeducational Battery

Subject

Reading Cluster

Math Cluster

Written Language

Knowledge Cluster
Standard Score $(M=100, S D=15)$

107

110

105

115 
APPENDIXB

Educational Placement Scale

1. Regular Classroom- with no basic change in teaching procedures

2. Consultation- regular classroom with specialists available for consultation with teacher (or parent) whenever needed.

3. Consultation and Direct Services- regular classroom with specialists available in the school to consult with the teacher and provide short-term services to the teacher.

4. Resource Room- regular classroom with resource room services (special education teacher or specialist providing supplemental instruction) provided on a continuing basis in which the student can participate for as much as two hours each day.

5. Part-Time Special Class- student enrolled in a special class for the majority of each day, but enters regular classroom for certain subjects.

6. Full-Time Special Class-student assigned to a self-contained special class on a full time basis.

7. Homebound/External Placement- student placed in a residential school, hospital program, or tutored at home, because he or she requires a more restrictive environnment not available within the context of regular or special public education. 
Table 1

ANOVA Table for Placement Scale: Base-Rate Conditions, Mixed Groups

\begin{tabular}{|c|c|c|c|c|c|}
\hline Source & $d f$ & SS & MS & $\underline{F}$ & $p$ \\
\hline Decision & 1 & .16 & 16 & .18 & .67 \\
\hline Error & 18 & 15.47 & .85 & & \\
\hline Base-rate & 1 & .04 & .04 & 1.65 & .22 \\
\hline Base-rate X Decision & 1 & .04 & .04 & 1.65 & .22 \\
\hline Error & 18 & .46 & 03 & & \\
\hline
\end{tabular}


Table 2

ANOVA Table for Placement Scale: Base-Rate Conditions, Intact Groups

\begin{tabular}{|c|c|c|c|c|c|}
\hline Source & $d f$ & SS & MS & $E$ & $\mathrm{p}$ \\
\hline Decision & 1 & .18 & .18 & .19 & 66 \\
\hline Error & 18 & 17.08 & .94 & & \\
\hline Base-rate & 1 & .05 & .05 & 1.00 & .33 \\
\hline Base-rate X Decision & 1 & .05 & .05 & 1.00 & .33 \\
\hline Error & 18 & 1.01 & .05 & & \\
\hline
\end{tabular}


Table 3

ANOVA Table for Placement Scale: Scatter Conditions, Mixed Groups

\begin{tabular}{|c|c|c|c|c|c|}
\hline Source & $d f$ & SS & MS & $E$ & $p$ \\
\hline Decision & 1 & 2.21 & 2.21 & 5.9 & .02 \\
\hline Error & 18 & 6.74 & .37 & & \\
\hline Scatter & 1 & 1.76 & 1.76 & 8.5 & .01 \\
\hline Scatter $X$ Decision & 1 & .06 & .06 & .31 & .58 \\
\hline Error & 18 & 3.67 & .20 & & \\
\hline
\end{tabular}


Table 4

ANOVA Table for Placement Scale: Scatter Conditions, Intact Groups

\begin{tabular}{|c|c|c|c|c|c|}
\hline Source & $d f$ & SS & MS & $\underline{E}$ & $\mathrm{E}$ \\
\hline Decision & 1 & 2.37 & 2.37 & 5.7 & .03 \\
\hline Error & 17 & 7.08 & 42 & & \\
\hline Scatter & 1 & 1.64 & 1.64 & 7.02 & .02 \\
\hline Scatter X Decision & 1 & .07 & .07 & .32 & .58 \\
\hline Error & 17 & 3.98 & .23 & & \\
\hline
\end{tabular}


Table 5

ANOVA Table for Probability: Base Rate Condition. Mixed Groups

\begin{tabular}{|c|c|c|c|c|c|}
\hline Source & $d f$ & SS & MS & F & $\mathrm{p}$ \\
\hline Decision & 1 & 1084.06 & 1084.06 & 1.08 & .31 \\
\hline Error & 18 & 18080.19 & 1004.45 & & \\
\hline Base-rate (BR) & 1 & 7.10 & 7.10 & .26 & .61 \\
\hline $\mathrm{BR} \times$ Decision & 1 & 12.71 & 12.71 & .47 & 0.50 \\
\hline Error & 18 & 486.26 & 27.01 & & \\
\hline Diagnosis (Dx) & $3.32^{\star}$ & 261852.05 & 29094.57 & 51.77 & .00 \\
\hline Dx $X$ Decision & $3.32^{\star}$ & 7489.16 & 832.13 & 1.48 & .16 \\
\hline Error & $59.83^{*}$ & 91042.09 & 561,98 & & \\
\hline$B A \times D x$ & $1.45^{\star}$ & 90.55 & 10.06 & .43 & .92 \\
\hline$B R \times D \times \times$ Decision & $1.45^{*}$ & 109.38 & 12.15 & .52 & .86 \\
\hline Error & $26.09^{*}$ & 3812.57 & 23.53 & & \\
\hline
\end{tabular}

*Geisser-Greenhouse adjustment 
Table 6

ANOVA Table for Confidence: Base-Bate Conditions. Mixed Groups

\begin{tabular}{|c|c|c|c|c|c|}
\hline Source & $\mathrm{df}$ & SS & MS & $\underline{F}$ & $\mathrm{p}$ \\
\hline Decision & 1 & 17.06 & 17.06 & .02 & .88 \\
\hline Error & 18 & 13208.57 & 733.8 & & \\
\hline Base Rate (BR) & $\uparrow$ & 173.98 & 173.98 & 2.53 & .13 \\
\hline BA $X$ Decision & 1 & .66 & .66 & .01 & .92 \\
\hline Error & 18 & 1236.18 & 68.67 & & \\
\hline Diagnosis (Dx) & $3.32^{*}$ & 13131.60 & 1459.07 & 5.29 & .00 \\
\hline Dx $\times$ Decision & $3.32^{*}$ & 1448.58 & 160.95 & .58 & .81 \\
\hline Error & $59.83^{*}$ & 44718.32 & 276.03 & & \\
\hline$B A \times D x$ & $1.45^{*}$ & 398.83 & 44.31 & 1.22 & .28 \\
\hline$B R \times D \times \times$ Decision & $1.45^{*}$ & 259.31 & 28.81 & .79 & .62 \\
\hline Error & $26.09^{*}$ & 5875.28 & 36.27 & & \\
\hline
\end{tabular}

*Geisser-Greenhouse adjustment 
Table 7

Mean Differences in Probability among Diagnoses: Base-rate Conditions, Mixed Groups

\section{Diaanosis}

ADHD BD Normal Other $L$ HI $\quad \mathrm{H} / \mathrm{L}$ Multi VI MR

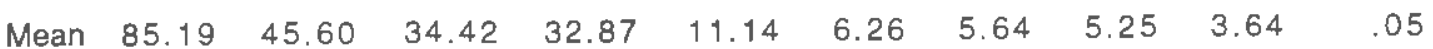

\begin{tabular}{|c|c|c|c|c|c|c|c|c|c|}
\hline ADHD & 39.59 & 50.77 & 52.32 & 74.05 & 78.93 & $\underline{79.55}$ & 52.32 & $\underline{81.55}$ & 85.14 \\
\hline$B D$ & & 11.18 & 12.73 & 34.46 & 39.34 & 39.96 & 40.35 & 41.96 & 45.55 \\
\hline Normal & & & 1.55 & 23.28 & 28.16 & 28.78 & $\underline{29.17}$ & 30.78 & 34.37 \\
\hline Other & & & & 21.73 & 26.61 & 27.23 & 27.62 & 29.23 & 32.82 \\
\hline$L D$ & & & & & 4.88 & 5.50 & 5.89 & 7.5 & 11.09 \\
\hline $\mathrm{H}$ ! & & & & & & 0.62 & 1.01 & 2.62 & 6.21 \\
\hline$S / L$ & & & & & & & 0.39 & 2.00 & 5.59 \\
\hline Multi & & & & & & & & 1.61 & 5.20 \\
\hline VI & & & & & & & & & 3.59 \\
\hline
\end{tabular}

Note: Underlined values are significant at $\mathrm{p}<.01$. 
Tabie 8

Mean Differences in Confidence among Diagnoses: Base-rate Conditions. Mixed Groups

Diagnosis

\begin{tabular}{|c|c|c|c|c|c|c|c|c|}
\hline MR & VI & Multi & $S / L$ & $\mathrm{HI}$ & Normal & D & $\mathrm{ADHD}$ & Other \\
\hline $\tan 99.49$ & 94.60 & 91.99 & 91.28 & 90.9 & 88.98 & 87.44 & 86.37 & 81.12 \\
\hline
\end{tabular}

$\begin{array}{llllllllll}\text { MR } & 4.89 & 7.50 & 8.21 & 8.59 & 10.51 & 12.05 & 13.12 & 18.37 & \underline{20.36}\end{array}$

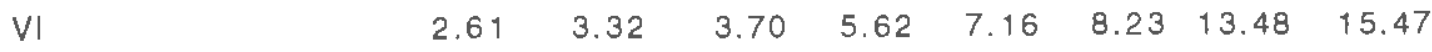

$\begin{array}{llllllll}\text { Multi } & 0.71 & 1.09 & 3.01 & 4.55 & 5.62 & 10.87 & 12.86\end{array}$

$\begin{array}{lllllll}S / L & 0.38 & 2.30 & 3.84 & 4.91 & 10.16 & 12.15\end{array}$

$\begin{array}{llllll}\mathrm{HI} & 1.92 & 3.46 & 4.53 & 9.78 & 11.77\end{array}$

$\begin{array}{lllll}\text { Normal } & 1.54 & 2.61 & 7.86 & 9.85\end{array}$

LD $\quad \begin{array}{rrr}1.07 & 6.32 & 8.31\end{array}$

$\begin{array}{lll}A D H D & 5.25 & 7.24\end{array}$

$\begin{array}{ll}\text { Other } & 1.99\end{array}$

Note: Underlined values are significant at $\underline{D}<.01$. 
Table 9

ANOVA Table for Probability: Base-Aate Conditions, Intact Groups

\begin{tabular}{|c|c|c|c|c|c|}
\hline Source & $d f$ & SS & MS & $\underline{F}$ & R \\
\hline Decision & 1 & 1112.89 & 1112.89 & 1.05 & .32 \\
\hline Error & 18 & 19037.10 & 1057.62 & & \\
\hline Base Rate (BR) & 1 & 6.35 & 6.35 & 1.06 & .32 \\
\hline BR $\times$ Decision & 1 & 11.70 & 11.70 & 1.96 & .18 \\
\hline Error & 18 & 107.64 & 5.98 & & \\
\hline Diagnosis (Dx) & $3.32^{*}$ & 260245.43 & 28916.16 & 46.33 & .00 \\
\hline Dx $\times$ Decision & $3.32^{*}$ & 6129.42 & 681.04 & 1.09 & .37 \\
\hline Error & $59.83^{*}$ & 101113.19 & 624.15 & & \\
\hline$B R \times D X$ & $1.45^{*}$ & 223.83 & 24.87 & 1.05 & .34 \\
\hline$B R \times D \times X$ Decision & $1.45^{*}$ & 224.35 & 24.92 & 1.05 & .34 \\
\hline Error & $26.09^{*}$ & 3837.73 & 23.69 & & \\
\hline
\end{tabular}

*Geisser-Greenhouse adjustment 
Table 10

ANOVA Table for Confidence: Base-Rate Conditions, Intact Groups

\begin{tabular}{|c|c|c|c|c|c|}
\hline Source & $d f$ & SS & MS & $\underline{F}$ & $\mathrm{D}$ \\
\hline Decision & 1 & 2.77 & 2.77 & .00 & .94 \\
\hline Error & 18 & 10682.59 & 593.48 & & \\
\hline Base-Pate (BR) & $t$ & 227.25 & 227.25 & 2.30 & .15 \\
\hline BR X Decision & 1 & 1.16 & 1.16 & .01 & .92 \\
\hline Error & 18 & 1777.49 & 98.75 & & \\
\hline Diagnosis (Dx) & $3.32^{*}$ & 14178.13 & 1575.35 & 5.50 & .00 \\
\hline Dx $\times$ Decision & $3.32^{*}$ & 975.09 & 108.34 & .38 & .94 \\
\hline Error & $59.83^{*}$ & 46378.22 & 286.28 & & \\
\hline$B R \times D x$ & $1.45^{\circ}$ & 467.64 & 51.96 & 1.49 & .15 \\
\hline$B R \times D \times \times$ Decision & $1.45^{*}$ & 340.79 & 37.86 & 1.09 & .37 \\
\hline Error & $26.09^{*}$ & 5636.14 & 34.79 & & \\
\hline
\end{tabular}

"Geisser-Greenhouse adjustment 
Table 11

Mean Differences in Probability among Diagnoses: Base-rate Conditions, Intact Groups

Diagnosis

ADHD BD Normal Other $D \quad H I \quad S / L$ Multi VI MR

$\begin{array}{lllllllllll}\text { M } & 84.83 & 44.39 & 35.71 & 33.71 & 9.26 & 7.01 & 5.57 & 5.26 & 4.05 & .05\end{array}$

\begin{tabular}{|c|c|c|c|c|c|c|c|c|c|}
\hline ADHD & 40.44 & 49.12 & 51.12 & 75.57 & 77.82 & 79.26 & $\underline{79.57}$ & $\underline{80.78}$ & $\underline{84.78}$ \\
\hline$B D$ & & 8.68 & 10.68 & $\underline{35.13}$ & 37.38 & 38.82 & 39.13 & 40.34 & $\underline{44.34}$ \\
\hline Normal & & & 2.00 & 26.45 & 28.70 & 30.14 & 30.45 & 31.66 & 35.66 \\
\hline Other & & & & 24.45 & 26.70 & 28.14 & 28.45 & 29.66 & 33.66 \\
\hline LD & & & & & 2.25 & 3.69 & 4.00 & 5.21 & 9.21 \\
\hline $\mathrm{HI}$ & & & & & & 1.44 & 1.75 & 2.96 & 6.96 \\
\hline$S / L$ & & & & & & & 0.31 & 1.52 & 5.52 \\
\hline Multi & & & & & & & & 1.21 & 5.21 \\
\hline VI & & & & & & & & & 4.00 \\
\hline
\end{tabular}

Note: Underlined values are significant at $\mathrm{p}<.01$ 
Table 12

Mean Differences in Confidence among Diagnoses: Base-rate Conditions, Intact Groups

Diagnosis

$\begin{array}{ccccccccccc} & \text { MR } & \text { VI } & \text { S/L } & \text { Multi } & \text { HI } & \text { Normal } & \text { D } & \text { ADHD } & \text { Other } & \text { BD } \\ \text { M } & 99.5 & 94.57 & 92.20 & 92.12 & 90.94 & 88.28 & 86.82 & 86.34 & 80.88 & 78.45\end{array}$

\begin{tabular}{|c|c|c|c|c|c|c|c|c|c|}
\hline MR & 4.93 & 7.30 & 7.38 & 8.56 & 11.22 & 12.68 & 13.16 & 18.62 & $\underline{21.05}$ \\
\hline Vl & & 2.37 & 2.45 & 3.63 & 6.29 & 7.75 & 4.60 & 13.69 & 16.12 \\
\hline$S / L$ & & & 0.08 & 1.26 & 3.92 & 5.38 & 5.86 & 11.32 & 13.75 \\
\hline Multi & & & & 1.18 & 3.84 & 5.3 & 5.46 & 11.24 & 13.67 \\
\hline $\mathrm{HI}$ & & & & & 2.66 & 4.12 & 4.60 & 10.06 & 12.49 \\
\hline Normal & & & & & & 1.46 & 1.94 & 7.40 & 9.83 \\
\hline LD & & & & & & & 0.48 & 5.94 & 8.37 \\
\hline $\mathrm{ADHD}$ & & & & & & & & 5.46 & 7.89 \\
\hline Other & & & & & & & & & 2.43 \\
\hline
\end{tabular}

Note: Underlined values are significant at $\underline{p}<.01$. 
Table 13

ANOVA. Table for Probability: Scatter Conditions, Mixed Groups

\begin{tabular}{|c|c|c|c|c|c|}
\hline Source & $d f$ & SS & MS & E & $\underline{\mathrm{Q}}$ \\
\hline Decision & 1 & 801.74 & 801.74 & .60 & 45 \\
\hline Error & 18 & 24004.33 & 1333.56 & & \\
\hline Scatter (S) & 1 & 1318.78 & 1318.78 & 5.57 & .03 \\
\hline $\mathrm{S} \times$ Decision & 1 & 364.24 & 364.24 & 1.54 & .23 \\
\hline Error & 18 & 4260.34 & 236.69 & & \\
\hline Diagnosis (Dx) & $3.13^{\circ}$ & 257930.07 & 28558.90 & 61.18 & .00 \\
\hline$D \times \times$ Decision & $3.13^{*}$ & 14171.42 & 1574.60 & 3.36 & .02 \\
\hline Error & $56.34 *$ & 7581.98 & 468.46 & & \\
\hline$S \times D x$ & $3.51^{*}$ & 4812.36 & 534.71 & 3.78 & .01 \\
\hline$S \times D \times \times$ Decision & $3.51^{*}$ & 2049.48 & 227.72 & 1.61 & .18 \\
\hline Error & $63.22^{\star}$ & 22945.39 & 141.63 & & \\
\hline
\end{tabular}

*Geisser-Greenhouse adjustment 
Table 14

Simple Effects for Diagnosis X Decision Interaction. Mixed Groups

\begin{tabular}{lccc} 
Diagnosis & Individual & Decision & Team \\
Normal & 18.56 & 2.55 & .01 \\
S/L & 78.65 & 87.25 & .14 \\
L & 65.77 & 59.13 & .57 \\
VI & 8.57 & 2.55 & .06 \\
HI & 16.70 & 12.05 & .48 \\
MR & 0.93 & .50 & .50 \\
BD & 15.45 & 5.05 & .05 \\
Other & 10.28 & 19.00 & .29 \\
Multi & 11.27 & 31.50 & .17 \\
ADHD & 27.39 & 5.68 & .01 \\
H. & & & \\
\hline
\end{tabular}


Table 15

Simple Effects for Scatter $X$ Diagnosis Interaction. Mixed Groups

\begin{tabular}{|c|c|c|c|}
\hline \multirow[b]{2}{*}{ Diagnosis } & \multicolumn{2}{|c|}{ Scatter } & \multirow[b]{2}{*}{$\mathrm{p}$} \\
\hline & Lower & Higher & \\
\hline Normal & 13.74 & 7.37 & .01 \\
\hline$S / L$ & 81.20 & 84.70 & .35 \\
\hline ம & 51.86 & 73.04 & .01 \\
\hline VI & 3.91 & 7.21 & .29 \\
\hline $\mathrm{HI}$ & 14.04 & 14.72 & 87 \\
\hline MA & .76 & .67 & .74 \\
\hline $\mathrm{BD}$ & 10.50 & 10.00 & .86 \\
\hline Other & 10.93 & 18.35 & 19 \\
\hline Multi & 18.05 & 24.72 & .21 \\
\hline $\mathrm{ADHD}$ & 16.28 & 16.79 & .80 \\
\hline
\end{tabular}


Table 16

ANOVA Table for Confidence: Scatter Conditions. Mixed Groups

\begin{tabular}{|c|c|c|c|c|c|}
\hline Source & $d f$ & SS & MS & $\mathrm{E}$ & $\mathrm{p}$ \\
\hline Decision & 1 & 8253.74 & 8253.74 & 25.95 & .00 \\
\hline Error & 18 & 5725.74 & 318.10 & & \\
\hline Scatter (S) & 1 & 285.61 & 285.61 & 2.68 & .12 \\
\hline$S \times$ Decision & 1 & 655.36 & 655.36 & 6.15 & .02 \\
\hline Error & 18 & 1917.75 & 106.5 & & \\
\hline Diagnosis (Dx) & $3.39^{*}$ & 11550.70 & 11283.41 & 5.53 & .00 \\
\hline Dx $\times$ Decision & $3.39^{*}$ & 3941.62 & 437.96 & 1.89 & .13 \\
\hline Error & $60.95^{*}$ & 37619.57 & 232.22 & & \\
\hline$S \times D x$ & $2.81^{*}$ & 798.68 & 88.74 & .92 & .43 \\
\hline$S \times D x \times$ Decision & $2.81^{*}$ & 1942.64 & 215.84 & 2.25 & .10 \\
\hline Error & $50.65^{*}$ & 115543.93 & 95.95 & & \\
\hline
\end{tabular}

"Geisser-Greenhouse adjustment 
Table 17

Mean Differences in Confidence among Diagnoses: Scatter Condtions. Mixed Groups

\section{Diagnosis}

$\begin{array}{ccccccccccc} & \text { MR } & \text { VI } & \text { Multi } & \text { BD } & \text { Normal } & \text { ADHD } & \text { S/L } & \text { Other } & \text { LD } & H I \\ \text { M } & 98.95 & 93.78 & 92.20 & 91.41 & 89.78 & 88.19 & 84.99 & 84.48 & 82.74 & 80.34\end{array}$

MR

5.17

6.75

7.54

$9.17 \quad 10.76$

$13.96 \quad 14.47$

$16.21 \quad 18.61$

Vi

$\begin{array}{ll}1.58 & 2.37\end{array}$

$4.00 \quad 5.59$

8.79

$9.3 \quad 11.04 \quad 13.44$

Multi

.79

2.42

$4.01 \quad 7.21$

9.3

$9.46 \quad 11.86$

BD

$$
1.63 \quad 3.22
$$

6.42

6.93

8.67

4.14

Normal

1.59

4.79

5.30

7.04

9.44

ADHD

3.20

3.71

5.45

7.85

$S / L$

.51

2.25

4.65

Other

1.74

6.93

LD

2.40

Note: Underlined values are signficant at $p<.01$. 
Table 18

ANOVA Table for Probability: Scatter Conditions, Intact Groups

\begin{tabular}{|c|c|c|c|c|c|}
\hline Source & $d f$ & SS & MS & $\underline{E}$ & $\underline{\mathrm{D}}$ \\
\hline Decision & 1 & 1080.76 & 1080.76 & 1.11 & .31 \\
\hline Error & 18 & 17501.90 & 972.33 & & \\
\hline Scatter (S) & 1 & 1095.94 & 1095.94 & 4.27 & .05 \\
\hline$S \times$ Decision & 1 & 497.07 & 497.07 & 1.94 & .18 \\
\hline Error & 18 & 4622.03 & 256.78 & & \\
\hline Diagnosis (Dx) & $3.29^{*}$ & 261479.67 & 29053.30 & 58.93 & .00 \\
\hline Dx $\times$ Decision & $3.29^{*}$ & 13932.27 & 1548.03 & 3.14 & .03 \\
\hline Error & $59.85^{\star}$ & 79864.53 & 492.99 & & \\
\hline$S \times D x$ & $3.38^{*}$ & 5507.23 & $61+.91$ & 4.34 & .00 \\
\hline$S \times D \times X$ Decision & $3.38^{*}$ & 1615.56 & $\$ 79.51$ & 1.18 & .32 \\
\hline Error & $60.79^{\star}$ & 22846.46 & 141.03 & & \\
\hline
\end{tabular}

*Geisser-Greenhouse adjustment 
Table 19

Simple Effects for Diagnosis X Decision Interaction: Scafter Conditions, Intact Groups

\begin{tabular}{lccc} 
Diagnosis & Individual & Decision & Team \\
\hline Normal & 20.23 & 2.55 & .01 \\
S/L & 79.23 & 87.25 & .19 \\
LD & 67.30 & 59.13 & .50 \\
VI & 7.99 & 2.55 & .08 \\
HI & 18.62 & 12.05 & .30 \\
MR & .84 & .50 & .31 \\
BD & 9.17 & 5.05 & .08 \\
Other & 14.43 & 19.00 & .19 \\
Multi & 12.77 & 31.50 & .01 \\
ADHD & 27.64 & 5.68 & .96
\end{tabular}


Table 20

Simple Effects for Scatter X Diagnosis Interaction: Scatter Conditions, Intact Group

$\begin{array}{lccc}\text { Diagnosis } & \text { Lower } & \text { Scatter } & \text { Higher } \\ \text { Normal } & 15.08 & 7.71 & .01 \\ \text { S/L } & 80.78 & 85.70 & .19 \\ \text { LD } & 52.47 & 73.96 & .01 \\ \text { VI } & 5.00 & 5.54 & .85 \\ \text { HI } & 15.61 & 15.05 & .86 \\ \text { MR } & .76 & .92 & .62 \\ \text { BD } & 9.84 & 8.51 & .16 \\ \text { Other } & 10.52 & 18.35 & .16 \\ \text { Multi } & 18.39 & 25.89 & .97 \\ \text { ADHD } & 16.70 & 16.62 & .62\end{array}$


Table 21

ANOVA Table for Confidence: Scatter Conditions, Intact Groups

\begin{tabular}{|c|c|c|c|c|c|}
\hline Source & $d f$ & SS & MS & $\underline{F}$ & $\mathrm{D}$ \\
\hline Decision & 1 & 8420.92 & 8420.92 & 22.99 & .00 \\
\hline Error & 18 & 6593.77 & 366.32 & & \\
\hline Scatter (S) & 1 & 350.23 & 350.23 & 2.94 & .10 \\
\hline $\mathrm{S} \times$ Decision & 1 & 565.75 & 565.75 & 4.76 & .04 \\
\hline Error & 18 & 2140.95 & 118.94 & & \\
\hline Diagnosis (Dx) & $3.66^{*}$ & 10505.85 & 1167.32 & 5.25 & .00 \\
\hline Dx $\times$ Decison & $3.66^{*}$ & 3327.01 & 3369.67 & 1.66 & .10 \\
\hline Error & $65.84^{*}$ & 35998.84 & 222.22 & & \\
\hline$S \times D x$ & $3.04^{*}$ & 600.88 & 66.77 & .67 & .79 \\
\hline$S \times D \times X$ Decision & $3.04^{*}$ & 1943.83 & 215.99 & 2.17 & .10 \\
\hline Error & $54.65^{\star}$ & 16120.39 & 199.51 & & \\
\hline
\end{tabular}

* Geisser-Greenhouse adjustment 
Table 22

Mean Differences in Confidence among Diagnoses: Scatter Condtion, Intact Groups

\section{Diagnosis}

$\begin{array}{ccccccccccc} & \text { MA } & \text { VI } & \text { Multi } & \text { BD } & \text { Normal } & \text { ADHD } & \text { S/L } & \text { D } & \text { Other } & H I \\ \text { M } & 98.26 & 93.95 & 91.53 & 91.62 & 89.7 & 87.86 & 85.08 & 84.11 & 83.79 & 80.51\end{array}$

\begin{tabular}{|c|c|c|c|c|c|c|c|c|c|}
\hline MA & 4.31 & 6.73 & 6.64 & 8.56 & 10.40 & 13.18 & 14.15 & 14.47 & 17.75 \\
\hline VI & & 2.42 & 2.33 & 4.25 & 6.09 & 8.87 & 9.84 & 10.16 & 13.44 \\
\hline Multi & & & .09 & 1.83 & 3.67 & 6.45 & 7.42 & 7.74 & 11.02 \\
\hline$B D$ & & & & 1.92 & 3.76 & 6.54 & 7.51 & 7.83 & 11.11 \\
\hline Normal & & & & & 1.84 & 4.62 & 5.59 & 5.91 & 9.19 \\
\hline$A D H D$ & & & & & & 2.78 & 3.75 & 4.07 & 7.35 \\
\hline$S / L$ & & & & & & & .97 & 1.29 & 4.57 \\
\hline LD & & & & & & & & .32 & 3.60 \\
\hline Other & & & & & & & & & 3.28 \\
\hline
\end{tabular}

Note: Underlined values are signficant at $\underline{0}<.01$. 


\section{BIBLIOGRAPHY}

Aspel, A. D. (1992). School Psychologist's Awareness of their Decision-making processes. Unpublished master's thesis. University of Rhode Island, Kingston. RI.

Algozzine, B., \& Ysseldyke, J. E. (1986). The future of the LD field: Screening and Diagnosis. Journal of Learning Disabilities. 19, 394-398.

Arkes, H. R. (1981). Impediments to accurate clinical judgment and possible ways to minimize their impact. Journal of Consulting and Clinical Psychology 49. (3) 323330 .

Barnett, D. W., (1988). Professional judgment: A critical appraisal. School Psychology Review, 6. 425-441.

Buchanan, L. J., \& Lindgreen, H. C. (1973). Brainstorming in large groups as a facilitar of children's creative responses. Journal of Psychology $\underline{83}, 117-122$.

Burns, C. W. (1990). Base rate theory and school psychology. School Psychology Review. 19(3), 356-366.

Clavelle, P. R., \& Turner, A. D. (1980). Clinical decision making among professional and paraprofessionals. Journal of Clinical Psychology 36, 833-858.

Chapman, L. J., \& Chapman, J. P. (1967). Genesis of popular but erroneous psychodiagnostic observations. Journal of Abnormal Psychology, 12, 193-204.

Dawes, R. M. (1986). Representative thinking in clinical judgment. Clinical Psychology Review, $\underline{6}, 425-441$.

Einhorn, H. J., \& Hogarth, R. M. (1978). Confidence in judgment: Persistance in the illusion of validity. Psychological Review. $85,395-416$.

Elstein, A. S. (1976). Clinical Judgment: Psychological research and medical practice. Science. 194, 695-700.

Fagley, N. S. (1988). Judgmental heuristics: Implications for the decision making of school psychologists. School Psychology Review, 17, 311-321.

Faust, W. L. (1959) Group versus individual problem solving. Journal of Abnormal and Social Psychology 59, 68-72.

Foster, G. G., Ysseidyke, J. E., Casey, A., Thurlow, M. L. (1984). The congruence between reason for referral and placement outcome. Journal of Psychoeducational Assessment, 2. 209-217.

Garb, H. N. (1989). Clinical Judgment, clinical training, and professional experience. Psychological Bulletin, 105, 387-396. 
Gauron, E. F., \& Dickinson, J. K. (1966). Diagnostic decision making in psychiatry. Archives of General Psychiatry, 14, 225-237.

Gresham, F. M., Carey, M. P., \& Reschley, D. J. (1987). Teachers as "tests": Classification accuracy and concurrent validation in the identification of learning disabled children. School Psychology Review. 16(4), 543-553.

Harari, O., \& Graham, W. K. (1975). Tasks and task consequences as factors in individual and group brainstorming. Journal of SecialPsychology 95, 61-65.

Hill, G. W., (1982). Group versus individual performance: Are $n+1$ heads better than one? Psychological Bulletin. 91, 517-539.

Holsopple, J. G., \& Phelan, J. G. (1954). The skills of clinicans in the analysis of projective tests. Journal of Clinical Psychology. 10, 307-320.

Kabler, M., \& Carlton, G. (1981). An investigation of existing multidisciplinary team decision-making practices. Unpublished manuscript, Ohio State University, Columbus.

Kahneman, D., \& Tversky, A. (1974). Judgment under uncertainty: Heuristics and Biases. Science, 185. 1124-1131.

Kaiser, S. M., \& Woodman, R. W. (1985). Multidisciplinary teams and group decisionmaking techniques: Possible solutions to decison-making problems. School Psychology Review, 14(4), 457-470.

Kendell, R. E. (1973). Psychiatric diagnosis: A study of how they are made. British Journal of Psychiatry, 122, 437-445.

Laughlin, P. R., \& Blitz, D. S. (1975). Individual versus dyadic performance on a disjunctive task as a function of initial ability level. Journal of Personality and Social Psychology, 31, 487-496.

Laughlin, P. R., Branch, L. G.,\& Johnson, H. H. (1969) Individual versus triadic performance on a unidimensional complementary task as a function of initial ability level. Journal of Personality and Social Psychology 12, 144-150.

Macmann, G. M., \& Barnett, D. W. (1985). Discrepency score analysis: A computer simulation of classification study. Journal of Psychoeducational Assessment, 3 , 363-375.

Michaelson, L. K., Watson, W. E., \& Black, R. H. (1989). A realistic test of individual versus group consensus decision-making. Journal of Applied Psychology. 74, 834839 .

O'Reilly, C., Northcraft, G. B., \& Sabers, D. (1989). The confirmation bias in special education eligibility decisions. School Psychology Review 18(1), 126-135.

Osborn, A. F. (1966). Applied Imagination: Principles and procedures of creative problem solving (3rd ed.). New York: Holt . 
Pfeiffer, S. I.(1980). The school-based interprofessional team: Recurring problems and some possible solutions. Journal of School Psychology, 18, 388-394.

Pfeiffer, S. I., \& Naglieri, J. A. (1983). An investigation of multidisciplinary team decision-making. Journal of Learning Disabilities, 10, 588-590.

Shaw, M. E. \& Ashton, N. (1976) Do assembly affects occur on disjunctive tasks? Bulletin of the Psychonomic Society, 8. 469-471.

Steiner, I. D. (1966). Models for inferring relationships between group size and potential group productivity. Behavioral Science.11, 273-283.

Taylor, D. W., Berry, P.C., \& Block, C. H. (1958). Does group participation when using brainstorming facilitate or inhibit creative thinking? Administrative Science Quarterly, 3, 23-37.

Tuckman, J., \& Lorge, I. (1962) Individual ability as a determinant of group superiority. Human Relations, 15, 45-51.

Turner, J. A. \& Koefoed, L. (1984). Decison-making, professional discipline, and program affiliation: Selection of an inpatient treatment alternative. Journal of Clinical Psychology, 40, 858-865.

Tversky, A. \& Kahneman, D. (1986). Judgment under uncertainty: Heuristics and biases. In H. R. Arkes \& K. R. Hammond (Eds.), Judgment and decision-making (pp. 38-55). New York: Cambridge University Press.

Vantour, J. A. C. (1976). A study of placement decisions for exceptional children determined by child study teams and individuals. Dissertation Abstracts International, 36, 6007-A.

Watson, W. Michaelson, L. K. \& Sharp, W. (1991). Member competence, group interaction, and group decision-making: A longitudinal study. Journal of Applied Psychology, 76, 803-809.

Yoshida, R. K., Fenton, K. S., Maxwell, J. P., \& Kaufman, M. J. (1978). Group decisionmaking in the planning team process: Myth or reality? Journal of School Psychology, 16, 237-244.

Yoshida, R. K. (1983). Are multidisciplinary teams worth the investment? School Psychology Review, 12, 137-143.

Ysseldyke, J. E., Algozzine, B., \& Allen, D. (1981). Participation of regular education teachers in special education team decision-making: A naturalistic investigation. Elementary School Journal, 82, 161-165.

Ysseldyke, J. E., Algozzine, B., \& Mitchell, J. (1982). Special education team decisionmaking: An analysis of current practice. Personnel and Guidance Journal, 308-313.

Ysseldyke, J. E., Algozzine, B., Richey, L., \& Graden, J. (1982). Declaring students eligible for learning disability services: Why bother with the data? Learning Disabilites Quartely, 5 , 37-44. 